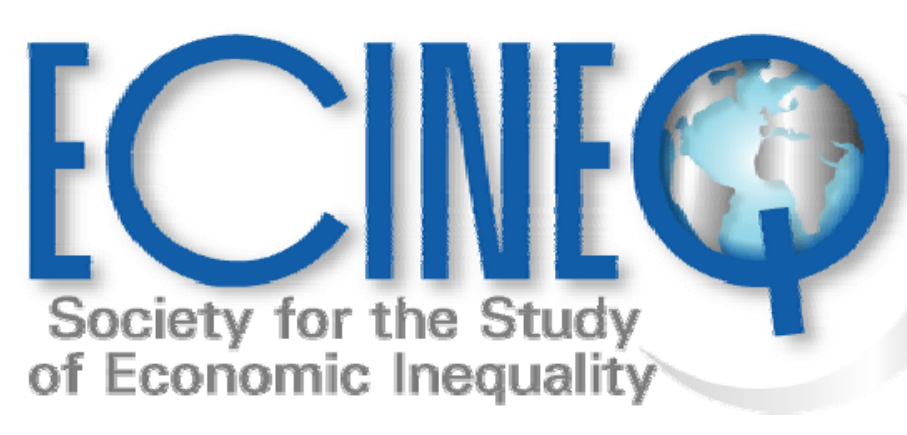

Working Paper Series

\title{
Cross-Country Income Mobility Comparisons Under Panel Attrition: The Relevance of Weighting Schemes
}

Luis Ayala

Carolina Navarro

Mercedes Sastre 


\title{
Cross-Country Income Mobility Comparisons Under Panel Attrition: The Relevance of Weighting Schemes ${ }^{*}$
}

\author{
Luis Ayala ${ }^{\dagger}$ \\ Instituto de E studios Fiscales / U niversidad Rey Juan Carlos \\ Carolina Navarro \\ U niversidad $\mathrm{N}$ acional de E ducación a D istancia \\ Mercedes Sastre \\ Instituto de $\mathrm{E}$ studios $\mathrm{F}$ iscales / U niversidad Complutense
}

\begin{abstract}
This paper aims to present an assessment of the effects of panel attrition on income mobility comparisons for some EU-countries by using the European Community Household Panel (ECHP). There are different possibilities of correcting the attrition problem by means of alternative longitudinal weighting schemes. The sensitivity of mobility estimates to these attrition correction procedures is tested in the paper. Our results show that ECHP attrition is characterised by a certain degree of selectivity but only affecting some variables and countries. Different probability models corroborate the existence of a certain non-random attrition. The model chosen to construct the longitudinal weights to correct attrition offers up rather different results than those obtained when Eurostat's longitudinal weights are used. Although attrition does not seem to have a great effect on aggregated mobility indicators, it does have a decisive effect on decomposition exercises. Finally, the tests conducted on income mobility indicators reveal a certain sensitivity to the weighting system used.
\end{abstract}

Keywords: Income mobility, attrition, European Community Household Panel. JE L : D 31, D63, J60

${ }^{*}$ Financial support for this research was provided trough the Ministry of Science and Technology (grant SEJ2004-07373-c03-03).

† Comesponding author. Luis Ayala luis.ayala@ ief.minhac.es 


\section{INTRODUCTION ${ }^{1}$}

Interest in the study of income distribution dynamics has grown considerably in recent years. Moving from a static analysis of welfare, inequality and poverty to a dynamic approach allows us to understand the distribution process better. More accurate assessments can also be made about the efficiency of public policies. Recent improvements in the study of the dynamics of inequality and poverty have been based on the advances made in the development of a solid body of theoretical work and the availability of new databases containing longitudinal information on households and individuals. Although some countries have a long-standing experience of longitudinal microdata -such as the Panel Study of Income Dynamics (PSID) of the United States, which was started up in the 1970s-, the 1990s heralded an unprecedented change as various countries created household surveys for the very first time with the aim of monitoring income level changes and living conditions over time.

There is no doubt that the setting up of the European Community Household Panel (ECHP) supposed a significant change for most European Union member states. It was the first household panel survey containing homogenous information on different countries and with a projected time span of almost a decade. In many of these countries, the only possibility of following households longitudinally up to then had relied on using administrative records or exploiting the rotating panel nature of some surveys. The detailed information of the ECHP makes possible the analysis of issues such as labour market transitions, individual decisions on fertility and marriage, changes in the health status, the evolution over time of housing conditions and facilities, life cycle fluctuations in income, welfare spells, the variety of exits from the educational system or changes in the position of households within the social scale.

However, some intrinsic characteristics of longitudinal surveys impose certain constraints on the analysis of most of the above-mentioned questions. The most relevant of these constraints is the loss of an important percentage of the initial sample as new waves of the survey are conducted. The loss of original observations over time (attrition) could entail a bias in the study of income dynamics if it has a selective character. Previous studies undertaken using the ECHP reveal that this source is not immune from the attrition problem, although its incidence

\footnotetext{
${ }^{1}$ Financial support for this research was provided trough the Ministry of Science and Technology (grant SEJ2004-07373-c03-03).
} 
does vary greatly among the countries that have conducted the survey [Hill and Willis (2001), Peracchi (2002), and Behr et al. (2002)].

As various dynamic processes are affected by the problem of sample attrition, there can be little doubt that it is a crucial issue when measuring income mobility. In the analysis of equality of opportunities, it is very different a situation where households having the greatest probability of leaving the sample are those with highest or lowest income from when most of the exits correspond to households with mean income levels. Similarly, if the objective is to analyse whether changes in income distribution over time are independent of the original situation, a relationship, for instance, between attrition and income or other socioeconomic characteristics could bias the results.

Regarding the specific case of the ECHP a key point in assessing the effects of attrition on income mobility or poverty dynamics is the growing attention paid by European policymakers to this source. The launching of National Action Plans to combat Poverty and Social Exclusion in the EU member states relied on the research of the ECHP. This is the only available source for comparative analysis of achievements in some of the Plans' goals like reducing persistent poverty. Political evaluation could be constrained by data variability due to sample attrition.

The aim of this paper is two-fold. On the one hand, it makes an attempt to assess the effects of attrition on income mobility and, on the other, it examines the different possibilities there are of correcting the attrition problem. Different longitudinal weighting systems to correct attrition exist, and these could produce very different results. In this paper we analyse the effects generated by using different weighting systems for both synthetic income mobility indicators as well as for the structure of income mobility. In as far as the ECHP's attrition problem differs substantially among the countries that have participated in this survey, we take different national samples into consideration. The use of a comparative framework enables us to verify not only how the problem of attrition can affect mobility in each country differently, but also to ascertain by up to what degree the problem can condition comparative analyses.

The study is structured as follows. The following section looks into the problem of ECHP sample attrition. Different procedures to correct its effects in dynamic analyses are estimated 
in the third section. The fourth section examines the consequences of attrition on the measurement of income mobility in a selected group of countries. The sensitivity of mobility estimates to attrition correction procedures is also assessed in this section. The study ends with a brief list of conclusions.

\section{ATTRITION IN THE EUROPEAN COMMUNITY HOUSEHOLD PANEL}

The European Community Household Panel (ECHP) was conducted by Eurostat in collaboration with national statistics agencies between 1994 and 2001. This database contains longitudinal information on income, as well as on a set of socio-economic and demographic characteristics on households and individuals. It therefore constitutes an obligatory point of reference for comparative studies on income structures and their dynamics over time in different countries. Of all the countries making up the ECHP, this paper focuses its attention on five different experiences: the United Kingdom, Germany, France, Italy and Spain. These are countries for which we have available empirical evidence supplied by various national studies. In addition, these countries represent different models regarding both the levels of inequality as well as the possible determining factors for mobility.

The ECHP was developed differently in each country. In Spain, France and Italy, among others, the survey was completely new, given the absence of comparable sources that could be adapted to the harmonisation requirements laid down by EUROSTAT. In Belgium, the Netherlands and Sweden ${ }^{2}$-which joined in 1997-, other already existing surveys were used to create the national samples. An unusual situation arose in Germany, the United Kingdom and Luxembourg, as there were two different panels during the first three waves. The ECHP stopped being conducted in these countries in 1997, and since then the data was gathered from already existing panels.

The problem of attrition is present in all the cases under consideration. By definition, this problem arises in longitudinal databases when there is non-response in interviews subsequent to the initial one. The result is a loss of observations over time that can hamper the following of an important segment of the sample. This kind of phenomena can have an influence on the results if the sample is no longer representative of the population under study. The problem of

\footnotetext{
${ }^{2}$ The Swedish data come from a cross-section survey which does not monitor individuals over time, thereby impeding longitudinal analyses from being conducted.
} 
attrition has been the object of study in national longitudinal surveys like the American PSID [(Becketti et al., 1988), (Fitzgerald et al., 1998 a,b)] and the German Socio Economic Panel (GSOEP) [(Pannenberg, 2001), (Rendtel and Büchel, 1994)], as well as in the ECHP itself [(Watson and Healy, 1999), (Buck and McCulloch, 2001), (Neukirch, 2002), (Behr et al. (2002), (Peracchi, 2002), (Nicoletti and Peracchi, 2002), (Rendtel, 2002)].

Focusing our attention on the countries chosen for analysis and taking individuals as the unit of reference, the available data show that both the evolution and scope of attrition are very different in each country under consideration (Graph 1). The presence of very different sample loss patterns stands out despite the fact that a certain degree of stability over time can be seen with year-on-year losses of almost 9\%, except for 1996 when most of the countries registered very important sample reductions. The differences in the scope of the problem are also striking. At the end of the last wave, only 45 percent of the initial observations for the ECHP as a whole remained. This percentage was greater in the case of the five countries under consideration, although notable differences among them can be observed. Generally speaking, countries having their own panel, like Germany and the United Kingdom, had much lower attrition rates (almost a third of the sample) than the rest. The case of Spain is outstanding, as it is at the opposite extreme with a loss of the initial sample amounting to 55 percent. In only eight years, the ECHP in Spain reached an attrition rate similar to the rate the SOEP in Germany (Rendtel, 2002) took sixteen years to get to or which the American PSID reached after more than two decades (Fitzgerald et al., 1998).

The progressive loss of initial sample observations can cause biases in the estimates. The magnitude of these effects depends on their influence on the sample's structure and, more specifically, on whether or not the bias is shared out randomly. As different studies have shown, attrition -even if it is high- only constitutes a problem if it is selective (JiménezMartín and Peracchi, 2002). If some socio-demographic categories do indeed exist in which the incidence of the loss of initial observations is above the average, possible estimates of the distribution process could be biased. Hence, if individuals with higher incomes have, for instance, a greater probability of leaving the sample, the trimming of the distribution could artificially reduce inequality -depending logically on the sensitivity of the indicator chosen.

An initial method to address the problem's incidence by socio-economic categories, is to analyse the extent of attrition within each specific group. In order to do so, the percentage of 
those staying in the panel can be analysed by population categories, taking into account both household as well as strictly individual characteristics. In general terms, there is a certain similarity in most countries' attrition patterns, though some differences do exist depending on the socio-economic categories under consideration (Table 1).

Unlike other national panels like the American PSID, there is no complete evidence that richest individuals remain in the panel for longer periods. While in countries like France, the United Kingdom and Germany there is a definite relationship with lower attrition among the richest deciles, Spain and Italy seem to coincide as both have a greater range of attrition variation by deciles and a poorly defined pattern. This singularity of the "Latin" model also appears when other variables are taken into account, such as the main source of income. The attrition rates of households whose main source of income is social transfers are above the average in Spain and Italy, while just the opposite happens in the other three countries. There are more similarities in the results for households dependent on earnings. The greater economic stability of this group, compared with those who mainly receive property income, increases the possibility of following these households. The greater volatility and uncertainty of the latter kind of income gives rise to a lower proportion of stayers, except in the case of Germany.

The hypothesis of households dependent on pensions having a higher probability of leaving the sample is similarly logical. Their attrition rates are above average in all the countries. It is therefore not surprising to find that the attrition profile by age groups in almost all countries shows considerably higher than average exit rates for those aged over 65 and, except for Spain, for households with younger heads. The ageing of the population is in fact one the characteristics having the greatest explanatory capacity for leaving the sample in other countries with household panels covering a longer period of time (Fitzgerald et al., 1998). The higher attrition rate of younger people is also a natural fact, given their greater economic and residential mobility.

Similarly, the distribution of attrition by household size and type does not appear to be random in any country. France, the United Kingdom and Germany have a pattern in which the highest attrition rates are for single-parent and smaller households. In Italy and, to a lesser extent, Spain, larger households have a higher probability of remaining in the sample. This fact is related to the greater stability of households with many children. All the countries are 
over-represented in the sample by couples with children. The results concerning marital status seem to corroborate this impression, with much lower percentages of households with divorced or separated heads remaining in the sample.

Regarding labour status, the stayer rates for two adults employed on a full-time basis are higher in all countries than for the other categories. Attrition is highest among households with no individuals working full-time. The divergence between the "Latin" model and the rest is also reflected in the distribution of attrition by the head educational attainment. While in France, the United Kingdom and Germany the highest levels of educational attainment seem to be associated with longer periods in the sample, in Spain and Italy education does not seem to be a factor for leaving it nor does there appear to be either a quadratic or lineal relationship with income. In the case of Spain, this result contrasts with those obtained using other sources like the Encuesta Continua de Presupuestos Familiares (Continuous Family Budget Survey) [Gradín et al., 2004].

Finally, given the natural association between household residential mobility and the probability of remaining in the sample, it seems appropriate to analyse the distribution of attrition by type of housing tenure. The frequency distribution appears to back the hypothesis that households owning their own dwelling have a lower attrition rate -associated to a lower level of residential mobility- than those living in rented housing.

\section{ADJUSTING FOR ATTRITION: LONGITUDINAL WEIGHTING SCHEMES}

Descriptive analysis shows that there are different population categories with higher attrition rates. It appears to be a certain selectivity in attrition, although for only some variables and countries. For the survey to be longitudinally representative, it is necessary to construct a longitudinal weighting system for each observation that reflects the probability of leaving the sample. Following along the same lines as previous papers (Fitzgerald et al., 1998, Pape, 2004, Gradín et al., 2004), we construct longitudinal factors based on the propensity score or probability of remaining in the survey, conditioned to a set of socio-economic characteristics $\left(\mathrm{Ps}_{\mathrm{i}}\right)$.

These longitudinal weights are therefore the result of estimating the probability of how a specific observation represents observations that have left the sample. Individuals having a 
greater likelihood of leaving the sample will be assigned a greater weight. The starting point is therefore some sort of linear probability estimation of remaining in the sample based on the characteristics of the individuals interviewed in the first wave. These probabilities can be estimated through a probit model. Using the inverse of such probabilities ${ }^{3}$, the longitudinal weight of each observation $i$ can be calculated as follows:

$$
\phi_{i, t}=\frac{\left(1 / P s_{i}\right)}{\frac{\sum\left(1 / P s_{i}\right)}{N_{t=1}}}=\frac{1}{P s_{i}} \cdot \frac{N_{t=1}}{\sum\left(1 / P s_{i}\right)}
$$

where $N_{t=l}$ represents the initial sample's size, and from which we can deduce that $\sum_{i} \phi_{i, t}=1$. The first term of Equation (1) is the propensity score weight, which is the inverse of the probability of remaining in the sample throughout the period under consideration. The second term seeks to ensure that the sum of the estimated weights is equivalent to the whole initial population. By generating a constant common factor for all observations of a wave, each observation's relative weight would not be modified.

Any variables identified as significant in the avilable empirical evidence on attrition have been included in the estimates made to obtain longitudinal weights. This, however, does not avoid a high degree of sensitivity in the results to both the choice of variables as well as their specification. Moreover, there is an additional problem concerning missing values. The probit models estimated exclude from the analysis those observations having missing values for some of the explanatory variables. It is impossible, therefore, to estimate a weight for such observations. An alternative lies in assigning to such observations the average value of the distribution of the variables for which information is unavailable. However, these imputations can generate important problems by fitting the information more to statistical criteria than to actual data. It seems to be more advisable to exclude from the regressions the variables having a higher proportion of non-response. Another choice also has to be made when estimating the models in order to obtain the weights, as it is possible to use both the information offered by data referring to household and heads characteristics, as well as strictly individual data.

\footnotetext{
${ }^{3}$ As Kalton and Brick (1994) point out, this procedure can turn out to be limited if the joint probability of a household leaving the sample and the individual probability of each of its members are not known correctly.
} 
This range of options requires the estimation of different models and choosing those which produce the most robust results among them. In this study we estimate two types of models. The first type takes into account household and heads characteristics. The presence of missing values in some variables, usually identified as associated to the probability of remaining in the sample, obliges us to examine the results produced depending on whether or not they are included in the model. This is why three different models are estimated using this first type of information. The first of these models includes household income by equivalent adult, the households' main source of income, the type of household, housing tenure and various of the head characteristics, including age, sex, martial status and educational attainment. As the latter variable registers the greatest number of missing values in all countries, a second model includes all of the same variables except educational attainment. The third model once again takes educational attainment into account and adds other household variables, such as household size, the number of children and the number of working adults.

The second type of model employs strictly individual characteristics, using the ECHP's personal file to do so ${ }^{4}$. The first sub-model uses net individual income, labour status, sex, marital status and the individual's educational attainment as explanatory variables for attrition. The second model adds age to these, and the third model additionally includes health status.

The results obtained from estimating the different models are shown in Tables 2 and 3. They corroborate the general conclusion that attrition is not random, as some variables register statistically significant effects. Estimates using information on the head and the household confirm some of the preliminary statistical analysis' features. However, a more obvious positive relationship can generally be observed of the probability of remaining in the ECHP with income, but negative when the latter is expressed in quadratic form except in the case of Italy. This probability is also generally lower in households that depend on property income, while dependence on pensions does not turn out to be significant in most of the countries. This does not seem to go against the idea that as the age of the household head increases, the lower the chances are of following the household over time. The results also allow to identify couples with children as the type of household with the highest probability of remaining in the sample once other characteristics are controlled, though some of these categories are not

\footnotetext{
${ }^{4}$ The calculation of weights for children and adults with incomplete questionnaires were therefore excluded from the estimates.
} 
significant in several of the countries under study. The situations of being separated or divorced are especially significant almost without exception, as they lower the probability of remaining in the sample. The same can be said for type of tenure, with a much lower probability of remaining in the sample if the house is rented.

The different educational variables' coefficients turn out to be significant in France, Germany and Spain. It is worth highlighting that there are no great changes in the remaining variables when the former is not considered in the estimates, as is the case in the second model proposed. Additionally, this second model offers better results than the third model estimated, which includes other relevant variables, such as the number of children, household size and the number of working adults.

The models constructed with the sample of adult individuals offers up similar results, except in the case of the sex variable (Table 3). The relationships with income, labour status or marital status are similar to the ones obtained in the above-mentioned models. In addition, the educational attainment variables seem to make little contribution to improving the estimates. The general situation does not change when age and health atatus are taken into account.

In order to calculate the longitudinal weights, we will use the second sub-model, which excludes educational attainment, so as to avoid reducing the number of observations. Nonetheless, it is convenient to test trough sensitivity analysis the range of possible variation with different weights. It also seems important to compare the longitudinal weights obtained through the probit models with those offered by the Eurostat microdata file. Although the procedures are apparently similar, there is no reason for the results to coincide.

Eurostat recommends using the so-called "base weights" of the last wave included in the analysis (variable rg003 of the microdata files) for longitudinal studies that include information on various waves ${ }^{5}$. Eurostat also point out that in principle it is possible to modify these "base weights" to take into account possible attrition, particularly if it is selective by age, sex, labour status or any other relevant characteristics. Eurostat considers that the base weights for 1996 would be sufficient for a longitudinal analysis that includes individuals

\footnotetext{
5 "ECHP UDB Manual: European Community Household Panel Waves 1 to 8. Survey years 1994 to 2001 ". Eurostat, DOC. PAN 168/2003-12.
} 
present in the panel's first three waves. Some authors, however, have questioned the weights estimated by Eurostat (Peracchi, 2002).

The construction by Eurostat ${ }^{6}$ of the "base weights" needed for longitudinal analyses was developed in various stages, which are described in Annex 1. The procedure consists of assigning sample people some initial weights for Wave 1 that are inversely proportional to the likelihood of being selected for the sample on the basis of the sample's initial design. Taking these initial weights as a reference and considering the non-response patterns among successive waves (calculated through a logistic regression), together with calibration procedures that take external controls into account, the base weights of the survey's successive waves are obtained. These weights take into account both the sample's design as well as the non-response patterns among successive waves.

Table 4 shows the correlation matrix of the different weights. The seven types of longitudinal weights respectively correspond to the weights offered by Eurostat $\left(\phi^{E}\right)$, the ones estimated using household and head characteristics $\left(\phi_{1}^{A}, \phi_{2}^{A}, \phi_{3}^{A}\right)$, and the weights estimated using individual characteristics $\left(\phi_{1}^{B}, \phi_{2}^{B}, \phi_{3}^{B}\right)$. The comparison is logically made by solely taking into account the individuals having complete questionnaires. The scant relationship of the results with Eurostat weights and the ones estimated using the two types of models is striking. This introduces the possibility of obtaining very different results if the estimates are very dependent on the weighting scheme.

The correlation among the weights corresponding to the first type of models is very high for all the countries. The inclusion or not of educational attainment does not seem to be relevant. This turns out to be a crucial issue in so far as choosing Model $A_{2}$ enables us to avoid eliminating a considerable number of observations in some countries. However, choosing individual instead of household characteristics does seem to have great importance. The correlation between both types of weights is positive but moderate, which could lead to a certain sensitivity in the results.

As was stated previously, the possibility of using all of the sample's observations suggests employing the second variety of the first type of models estimated. This sub-model is not very

\footnotetext{
6 "Construction of weights in the ECHP". Eurostat DOC.PAN 165/2003-06.
} 
sensitive to the inclusion or not of other household variables. Its weights, however, are somewhat different from those resulting from taking into consideration strictly individual information. They don't show at all a relationship with Eurostat weights. A simple way of verifying the reliability of the estimated weights is to compare the initial frequency distribution with the distribution that would result from applying to the initial wave the weighting system estimated for the individuals that stayed in the sample during the whole period. If the specification of the model used as reference is correct, there should a priori be many coincidences between the initial frequency distribution and the balanced panel's distribution weighted by the factors constructed with the propensity score.

Table 5 shows the frequency distributions of the various variables for the ECHP's first wave using different weighting systems. The first column for each country reflects the data of the first wave of the panel without any weighting at all $(\phi=1)$. The second column shows the first wave's frequency distribution weighted with the cross-sectional weights supplied by Eurostat $\left(\phi=\phi^{E}\right)$. The third column reflects the same wave's frequency distribution for the balanced panel sub-sample adjusted with Eurostat's longitudinal weights. The first wave's balanced panel frequencies adjusted with the weights estimated with the sub-model $A\left(\phi=\phi_{2}{ }^{A}\right)$ appear in the last column for each country.

Firstly, it seems reasonable to compare the frequency distribution of the balanced panel sample's first wave using the estimated longitudinal factors (column 4) with the first wave's unweighted distribution ${ }^{\circ}$ (column 1). The data for the different countries reveal a high degree of symmetry among the frequency distributions for a wide-ranging set of characteristics. The deviations are very small despite the fact that the fit for each country is different.

We can also compare the frequencies of the first wave's balanced panel sample weighted by the longitudinal factors of Eurostat (column 3) with the first wave's frequency distribution weighted with the cross-sectional weights also supplied by Eurostat (column 2$)^{7}$. The overall result is that there is a notable distance between the original frequencies and those resulting from applying Eurostat's longitudinal weights to the balanced panel's sample. Their use

\footnotetext{
${ }^{7}$ Although in theory the longitudinal weights supplied by Eurostat have the same logic as the models we estimate in this paper, other conditioning factors could in practice intervene which are related to the method of estimation, giving rise to some differences. Likewise, Eurostat's longitudinal weights not only make an effort to correct the problem of attrition but also aim to correct the initial wave's non-response bias (see Annex 1).
} 
entails assigning a greater relative weight to specific population categories. In the case of Germany, the United Kingdom and France, the richest deciles are given a greater weight. In the case of Italy and Spain, there does not appear to be a clear pattern. There are also remarkable changes regarding the households' main source of income. In general terms, a greater weighting can be seen for households having earnings as well as a reduction in the proportion of pensioners. There is not a clear common pattern of change for property income. Eurostat's weights also modify the distribution by household type, with single-individual and single-parent households losing weight. The opposite happens with households having a greater number of children. Divergences in the distribution by age can also be discerned when these weights are applied. The relative importance of individuals under 65 years of age increases, while that of older people is reduced. Generally speaking, applying the longitudinal weights of Eurostat produces a more limited fit in the categories for which greater problems of sample attrition were observed.

To sum up, different ways of correcting the problem of selective attrition exist, which can affect the sample's structure. This fact has significant implications for static income distribution analyses and could a priori have even greater consequences for dynamic analyses.

\section{ATTRITION AND INCOME MOBILITY}

The comparative study of income dynamics is one of the main possibilities opened up by the ECHP's development. Various questions are thrown up by static analyses on inequality that can only be answered from a dynamic perspective. The possible conclusions that can be reached from the application of dynamic methodologies on individual income are, nevertheless, highly conditioned by the possibility of the ECHP's sample losing representativeness nature as a result of attrition. Although the preliminary analysis showed a different incidence of attrition in each country, there is enough evidence to affirm that attrition is selective in most cases. Non-random attrition could affect longitudinal analyses on households and individuals. To a great extent, the answers to questions like to what degree and what kind of income mobility are prevalent in a specific society depend on the quality and representativeness of the data. 
Two questions are related to the effects of attrition on income mobility. Firstly, it should be tested whether or not mobility indicators change substantially as a result of certain groups of individuals progressively leaving the sample. Secondly, it can be estimated whether the longitudinal weighs estimated in the previous section could correct these biases.

A common procedure for estimating the effects of attrition on the measurement of income mobility consists of dividing the sample according to the individuals remaining in successive waves and comparing the results estimated for the resulting sub-samples. Supposing we have longitudinal income and individual characteristics data available for the period $t=1, \ldots, T$, then we can divide the individuals present in the first wave of the panel into two sub-samples. The first of these would include the individuals who remain in all of the panel's waves (subsample $p$ or balanced panel), which in our study would comprise the ECHP's eight waves from $t=1$ to $t=8$. The second sub-sample (smaller than the previous one) would be made up of the individuals who were present in the first wave but left the sample in any of the subsequent waves (sub-sample $k$ ). The logic behind this exercise is simple and has been developed by other authors (Fitzgerald et al. 1998a, Behr et al. 2003).

If $\mathrm{R}_{\mathrm{n}}^{+}$is the set of possible distributions for a population made up of $\mathrm{N}$ individuals, then $\mathrm{N} \equiv\{1,2, \ldots, n\}, \mathbf{X}=\left(\mathrm{x}_{1}, \mathrm{x}_{2}, \ldots, \mathrm{x}_{\mathrm{n}}\right) \in \mathrm{R}_{\mathrm{n}}^{+}$is the initial distribution sorted by income levels and $\mathbf{Y}=\left(\mathrm{y}_{1}, \mathrm{y}_{2}, \ldots, \mathrm{y}_{\mathrm{n}}\right) \in \mathrm{R}_{\mathrm{n}}^{+}$corresponds to the income distribution in a second period. It is possible to assign an earnings vector (xi,yi) to any individual $\mathrm{i} \in \mathrm{N}$ for the whole period, reflecting that individual's income in the initial and final distributions. The transformation $\mathbf{X} \rightarrow \mathbf{Y}$ generates a variation in individual income over time. This transformation may entail both variations in each individual's final income, as well as changes in his/her position in the income scale, which can be summed up through a mobility index (M).

Let us suppose then that there are available data for the whole period $t=1, \ldots, T$ and we wish to analyse income mobility in the time period that elapses between two time intervals $t=a$ and $t=b$, with $\mathrm{a}<\mathrm{b}$. If $\mathbf{X}$ is the distribution corresponding to period $a$ and $\mathbf{Y}$ is the distribution corresponding to period $b$, there are two possible transformations. The first transformation, $\mathbf{X}_{\mathbf{K}} \rightarrow \mathbf{Y}_{\mathbf{K}}$, includes the individuals who remained in the sample in the successive waves included between periods $a$ and $b$. Transformation $\mathbf{X}_{\mathbf{P}} \rightarrow \mathbf{Y}_{\mathbf{P}}$ is the income transformation corresponding to the individuals who remained in the sample during all the waves (from $t=1$ 
to $t=T)$. We can affirm that there is an attrition effect on mobility if $\mathrm{M}\left(\mathbf{X}_{\mathbf{K}} \rightarrow \mathbf{Y}_{\mathbf{K}}\right) \neq \mathrm{M}\left(\mathbf{X}_{\mathbf{P}} \rightarrow\right.$ $\mathbf{Y}_{\mathbf{P}}$ ), where $\mathbf{M}$ is the mobility indicator associated with income transformation $\mathbf{X} \rightarrow \mathbf{Y}$.

There are various indices enabling to synthesise individual income transformations through a single indicator. Each of them reflects a different dimension of mobility. The relationship between cross-sectional and longitudinal inequality was formulated by Shorrocks (1978a) by means of an income rigidity index that compares inequality in different sub-periods $\left(t_{k-1}, t_{k}\right)$ within a specific time interval $\left(t_{0}, t_{n}\right)$ with the inequality that results from taking into account the aggregated income of each individual throughout the whole period:

$$
R=\frac{I\left[x\left(t_{0}, t_{n}\right)\right]}{\sum_{i=1}^{n} w_{k} I\left[x\left(t_{k-1}, t_{k}\right)\right]}
$$

where $I$ is an inequality indicator, $\boldsymbol{X}$ is an income distribution and $w_{k}$ a weighting factor for the aggregated earnings received in each sub-period $k\left(w_{k}=\mu\left(\mathbf{x}_{t k-1, t k}\right) / \mu\left(\mathbf{x}_{t 0, t n}\right)\right)$.

Another approach attempts to estimate some kind of statistical relationship between individual income of the final $(\mathbf{Y})$ and initial distributions $(\mathbf{X})$. The Hart Index is defined as the complement of the correlation between each period's income (in logarithms). A third approach emphasises changes of state within the income distribution by constructing transition matrices. The most common index is the Shorrocks Index (1978b):

$$
M(P)=\frac{n-\operatorname{tr}(P)}{n-1}
$$

where $t r$ is the trace of the transition matrix and $n$ is the number of percentiles, and therefore of the matrix's rows and columns. Another indicator was proposed by Bartholomew (1973), which averages out the movements beyond the transition matrix's diagonal:

$$
B I=\sum_{l=1}^{n} \sum_{j=1}^{n} p_{l j}|l-j|
$$


where $p_{l j}$ represents transitions towards percentiles that are different from the initial percentile. The greater the index's value, the greater the degree of mobility. The percentage of households that remain in the same decile also turns out to be an intuitive indicator.

As was mentioned above, indicators for the two sub-samples $(k, p)$ can be compared to observe the effects of attrition on income mobility without for the moment using any kind of weighting to offset the loss of observations. Lower mobility in sub-sample $p$ would be coherent with the notion that individuals who exit the sample are those with greater income fluctuations.

Estimating the different types of mobility indicators between waves 1 and 4 with the two subsamples (in this case sub-sample $k$ would include the individuals present in at least the first four waves and sub-sample $p$ the individuals present in all the panel's waves) reveals some interesting results concerning the effects of attrition (Table 6). Firstly, it seems that the sample losing a considerable number of observations does not introduce a remarkable bias in comparisons among countries. Re-rankings among the countries are not produced and the variance of the different national indicators' values is not substantially modified. Nevertheless, a common pattern of results is repeated in all the countries: observed mobility is systematically lower in the balanced panel sample than in the sample made up of individuals present in at least the first four waves. This fact seems to bear out the notion that the individuals who leave the sample have greater mobility than those that stay in it. The only exception to this is France, which repeats this behaviour with the income rigidity indicators, but which shows greater mobility in the balanced panel when the transition matrices are used. In any event, the differences among the indicators with the different sub-samples are small, especially in Spain and Germany. Only in the UK does attrition seem to have more important effects on the magnitude of observed mobility, especially when it is approached through correlation indicators.

The main effect of attrition on mobility estimates, however, is not so much related to the indices' values but to the decomposition of mobility into structural components or population partitions. Fields and Ok (1996) defined an index that results from the sum of the absolute values of each individual's or household's changes in income: 


$$
m_{n}(x, y)=\frac{\sum_{i=1}^{n}\left|\log x_{i}-\log y_{i}\right|}{n}
$$

An important feature of this index is its additively decomposable nature:

$$
m_{n}(x, y)=K(x, y)+T(x, y)=\frac{1}{n} \sum_{i=1}\left(\log y_{i}-\log x_{i}\right)+\frac{2}{n} \sum_{i \in L}\left(\log x_{i}-\log y_{i}\right)
$$

where $\mathrm{k}(\mathrm{x}, \mathrm{y})$ sums up the income changes caused by economic growth and $T(\mathrm{x}, \mathrm{y})$ reflects the total movement of income attributable to transfers from winners to losers ${ }^{8}$.

This index can also be decomposed by population groups. If the population is divided into $J \in\{1, \ldots, n\}$ partitions, $\forall j=1, \ldots, J \mathrm{y} \mathrm{x}^{\mathrm{j}}, \mathrm{y}^{\mathrm{j}}$ :

$$
m_{n}\left[\left(x^{1}, \ldots, x^{j}\right),\left(y^{1}, \ldots ., y^{j}\right)\right]=\sum_{j=1}^{J}\left(\frac{n_{j}}{n}\right) m_{n j}\left(x^{j}, y^{j}\right)
$$

Therefore, the index can be desaggregated as a weighted average of mobility in the different groups, with the weights being each group's population share.

Estimating the different mobility components in the two sub-samples adds some interesting nuances to the results mentioned above (Table 7). As with the aforementioned indicators, the Fields and Ok index is lower in the case of sub-sample $p$, although the differences are small. The contribution of the transfer component is greater in both sub-samples, except in the case of the United Kingdom. Despite the apparent absence of great differences in the aggregated mobility indicator, attrition nonetheless does produce some changes in each component's relative contribution. In some cases, it increases the role of growth (France and Italy) and in others the contribution of transfers (Spain).

The results corresponding to each group's mobility indicator $\left(M_{i}\right)$ and its contribution to overall mobility in each country $\left(C_{i}\right)$ are shown in Tables 8 and 9 . If we focus our attention on

\footnotetext{
${ }^{8}$ Multiplying by two reflects that each loss of income of an individual or household is converted into a gain for another.
} 
mobility by household type, almost all countries register significant differences depending on whether the balanced panel or the panel of those present in at least the first four waves is taken into account. Attrition produces a lower contribution to the mobility of individuals living alone, those above 65 years of age and those belonging to single-parent households in all countries, except in France and the United Kingdom. However, there are divergences among countries in the case of young people living alone and couples without children.

The differences among the indicators obtained with each sample are logically lower for the characteristics having a lower number of categories, although relevant differences can also be observed. These crop up in the case of the different sources of income in all countries, although without a common pattern predominating. Only pensions seem to register slightly lower mobility indicators with the balanced panel. In general terms, attrition seems to increase the mobility of individuals living in households with heads in the intermediate age groups and hardly changes differences by sex at all. Changes in the indicators corresponding to marital status are also very slight, and exits from the sample give rise to a slight increase in the contribution to overall mobility made by individuals living in households having married heads and, on the other hand, to a decrease in the relative contribution made by separated or divorced individuals. The differences are negligible in the remaining categories, with the exception of housing tenure. Attrition generally leads to an increase in the contribution made to mobility by people with owned housing and to a reduction in the case of rented housing.

Though attrition does not appear to have much incidence on general mobility indicators, comparing the results of the two sub-samples reveals that the problem can introduce biases of a certain magnitude to decomposition exercises of income movements over time. It therefore seems reasonable to introduce attrition correction procedures to try and limit these biases. Following the options adopted in the previous analysis, we have three different alternatives: not weighting at all $\left(\phi_{i}^{l}=1\right)$, using Eurostat's longitudinal weights $\left(\phi_{i}^{l}=\phi^{E}\right)$ and estimating weighting systems based on the conditional probability of remaining in the sample $\left(\phi_{i}^{l}=\phi_{2}^{A}\right)$. The relevant question is whether any important changes are made to general indicators and hence to the analysis' robustness when a specific weighting procedure is chosen. Calculating the same battery of mobility indicators as in the previous case is a good way of illustrating the possible effects of alternative attrition correction procedures. In order to take advantage of all 
the information available and to construct long-term mobility indicators, we now focus our attention on the ECHP's available waves (Table 10).

In the case of the Hart Index, changes are produced when we go from not taking into consideration longitudinal weights to using the factors estimated with regression models. This index shows greater mobility with the latter weights than without them, changing the results and widening their range of variation. Additionally, some re-rankings are registered, such as for France, which, after Spain, becomes the country with the highest mobility using this index, or for Germany with just the opposite effect. The changes are much more moderate when mobility is analysed from the standpoint of income rigidity (Shorrocks Index) or from transitions in the income scale. If the former of these approaches is adopted, the general situation is of very moderate changes in the figures. Nevertheless, some initial values are modified either upward (Germany and the United Kingdom) or downward (France) without giving rise to a re-ranking of countries. In the case of transition matrices, the indices seem to be insensitive to the choice of our estimated weights or not using individual weights.

The results change when Eurostat's longitudinal weights are used. The inexistent relationship of these weights with those estimated through regression models now manifests itself in appreciable differences in the mobility indicators and in a re-ranking of countries. If the factors put forward by Eurostat are used, Spain, for instance, would change from being a country in a middle-ranking position to being the country with the largest number of transitions when the percentage of individuals remaining in the same or in the neighbouring decile is taken as a reference.

Given these results, it is to be expected that the results corresponding to decomposition exercises by types of mobility or population sub-groups could be affected by the use of a particular longitudinal weighting system. The results of decomposing the Fields and Ok index into the double components of growth and transfers seem to depend on the decisions adopted. As is the case of the general indices, there is a range of relatively small differences when the estimated weights are chosen instead of unitary weights, and they are of a greater magnitude when the indices are calculated using Eurostat's weights. In the former case, the relative contribution to mobility made by the two components are changed, though these changes are slight. Eurostat's weights systematically raise the contribution made by growth, except in the case of the United Kingdom. 
The results of the decomposition by population sub-groups seem to be more sensitive. Despite the fact that the differences in each category's specific mobility indices are, generally speaking, relatively small, the same cannot be said for each group's demographic weight. This event makes the total contribution made to mobility change substantially in various groups when the weighting system is also changed (Tables 12, 13 and 14). For instance, changing from unitary weights to the weights estimated through the regressions systematically raises the relative contribution made by single-person households. It also reduces the contribution made by individuals dependent on earnings and that of individuals whose main source comes from property income. The change produced when the weights estimated by age partitions are used is less significant, except for the generally greater contribution made by young people and women. It is also worth highlighting the greater contribution made to mobility by the estimated weights in the case of population groups with a greater likelihood of having higher income volatility over time, like separated or divorced heads or those who live in rented housing.

This pattern of change differs substantially from the pattern that arises when the unweighted results are compared with the results derived from using Eurostat's longitudinal weights. The differences in the relative contribution made by each group are much more pronounced, and in general terms, they do not follow a fixed pattern. Our estimates therefore confirm a great sensitivity of the results to the weighting system chosen, especially in the case of more disaggregated income mobility analyses.

\section{CONCLUSIONS}

The increasing availability of longitudinal data has given rise to the development of new lines of research that attempt to explore different aspects connected with inequality and social welfare. Among other dynamic processes, income mobility has received a considerable amount of attention, resulting in notable empirical work based on a significant improvement in analytical methods and techniques. A great deal of this work, however, has been conditioned by the natural constraints of this kind of information. The loss of observations as new waves are conducted usually entails a change in the final observations' representativeness, which is greater as the probability of remaining in the sample becomes more selective. The main objective of this paper has been to make an attempt at examining to 
what extent the European Community Household Panel is affected by a non-random attrition problem and to try and correct its possible incidence on the study of income mobility in a group of European Union member states.

The different estimates seem to suggest that the attrition observed in the ECHP is characterised by a certain degree of selectivity that only affects some variables and countries. The loss, though partial, of the sample's representative nature as the different waves of the survey were conducted has led us to construct a longitudinal weighting system for each observation dependent on the probability of remaining in the survey. In order to do so, different probability models were constructed that corroborate the existence of a certain not totally random kind of attrition. The model chosen to construct the longitudinal weights to correct non-random attrition offers up rather different results than those obtained when Eurostat's longitudinal weights are used, while seemingly generating a high degree of symmetry in the initial sample's frequency distributions. This fact warns us of the possible sensitivity of mobility analysis results when one or other procedure is chosen.

As a matter of fact, the tests conducted on income mobility reveal a certain sensitivity to the weighting system used. Although attrition does not seem to have a great effect on aggregated mobility indicators, it does have a decisive effect on decomposition exercises. They are particularly relevant to analyse social models and assess public policies. In the light of the calculations made, correcting results with weighting systems directly designed from estimating the probability of remaining in the sample could make a contribution toward correcting the problem. Nonetheless, the differences registered for the mobility indicators depending on the type of weighting used, which are particularly marked in some population segments, oblige us to carefully consider the deductions that can be made in roder to improving the diagnosis of the processes analysed or regarding possible changes in the design of public interventions. 


\section{References}

Baltagi, B.H. (2001): Econometric Analysis of Panel Data, 2a edición, John Wiley \& Sons.

Bartholomew, D.J. (1973): Stochastic Models for Social Process, $2^{\circ}$ ed. Londres: John Wiley and Sons.

Becketti, S., Gould, W., Lillard, L. y Welch, F. (1988): “The Panel Study of Income Dynamics after 14 years: An evaluation”, Journal of Labor Economics, 6, pp.472-492.

Behr, A., Bellgardt, E. y Rendtel, U. (2002): "Extent and determinants of panel attrition in the European Community Household Panel”, Working Paper 7, CHINTEX.

Behr, A., Bellgardt, E. y Rendtel, U. (2003): “Comparing poverty, income inequality and mobility under panel attrition. A cross country comparison based on the European Community Household Panel", Working Paper 12, CHINTEX.

Buck, N. y McCulloch, A. (2001): "Country differences and survey differences in the analysis of attrition in panel studies", Chintex Workshop, November 2001.

Davey, A., Shanahan, M.J. y Schafer, J.L. (2001): "Correcting for Selective Nonresponse in the National Longitudinal Survey of Youth Using Multiple Imputation”, Journal of Human Resources, 36, pp. 500-519.

Fitzgerald, J., Gottschalk, P. y Moffitt, R. (1998a): "An Analysis of Sample Attrition in Panel Data The Michigan Panel Study of Income Dynamics", Journal of Human Resources, 33, pp. 251-299.

Fitzgerald, J., Gottschalk, P. y Moffitt, R. (1998b): "The Impact of Attrition in the Panel Study of Income Dynamics on Intergenerational Analysis", Journal of Human Resources, 33, pp. 300-344.

Gradín, C., Cantó, O., y Del Río, C. (2004): “Inequality, poverty and mobility: choosing income or consumption as welfare indicators". Papeles de Trabajo del Instituto de Estudios Fiscales nº 18/04.

Hill, D.H. y Willis, R.J. (2001): "Reducing Panel Attrition. A Search for Effective Policy Instruments", Journal of Human Resources, 36 (3), pp. 416-438.

Kalton, G., y Brick, J.M. (1994): "Weighting schemes for household panel surveys". Proceedings of the Survey Research Methods Section of the American Statistical Association, pp. 785-790. Alexandria, VA: American Statistical Association.

Matyas, L. y Sevestre, P. (eds.) (1992): The Econometrics of Panel Data, Kluwer Academic Publishers: The Netherlands.

Neukirch, T. (2002): "Nonignorable attrition and selectivity biases in the Finnish subsample of the ECHP. An empirical study using additional register information", Working Paper 5, CHINTEX.

Nicoletti, C. y Peracchi, F. (2002): "A cross-country comparison of survey nonparticipation in the ECHP", Working Papers of the Insitute for Social and Economic Research, paper 2002-32, Colchester: University of Essex.

Pannenberg, M. (2001): "Documentation of sample sizes and panel attrition in the German Socio Economic Panel (GSOEP) (1984 until 2000)", DIW Research Notes,6. 
Pape, A. (2004): “How Does Attrition Affect the Women's Employment Study Data?", National Poverty Center, University of Michigan (mimeo).

Peracchi, F. (2002): “The European Community Household Panel: A review", Empirical Economics, 27, pp. 63-90.

Pierret C.R. (2001): "Event History Data and Survey Recall. An Analysis of the National Longitudinal Survey of Youth 1979 Recall Experiment”, Journal of Human Resources, 36, pp. 439-466.

Rendtel, U. (2002): “Attrition in Household Panels: A Survey”, Working Paper 4, CHINTEX.

Rendtel, U. y Büchel, F. (1994): "Test for non-ignorable panel attrition and their application on wage estimates fro the German Socio Economic Panel (GSOEP)", DIW Discussion papers, 89.

Romeo, C.J. (2001): "Controlling for Seam Problems in Duration Model Estimates With Application to the Current Population Survey and the Computer Aided Telephone Interview Overlap Survey", Journal of Human Resources, pp. 467-499.

Shorrocks, A.F. (1978a): "Income Inequality and Income Mobility", Journal of Economic Theory, 19, pp. 376-393.

Shorrocks, A.F. (1978b): “The measurement of mobility”, Econometrica, 46, pp. 1013-1024.

Watson, D. y Healy, M. (1999): Sample attrition between waves 1 and 2 in the European Community Household Panel Study, European Commission, Luxembourg, 118/99.

Wu, L.L., Martin, S.P. y Long, D.A. (2001): "Comparing Data Quality of Fertility and First Sexual Intercourse Histories”, Journal of Human Resources, 36, pp. 520-555. 


\section{ANNEX I: Construction of Longitudinal Weights in the ECHP}

The construction by Eurostat of the "base weights" needed for longitudinal analyses was developed in various stages ${ }^{9}$.

1.- Firstly, "initial weights" were constructed for each individual in the sample (wstart sp). In the initial wave, this weight is the "design weight" (which is inversely proportional to the probability of being selected for the sample based on the sample's initial design). All the individuals present in the first wave are sample people and consequently have a initial weight which is greater than zero. In the remaining waves, the initial weight of each individual is his/her "base weight" (rg003) in the previous wave (for sample people this is positive and for non-sample people it is zero).

2.- Secondly, the "individual provisional weights" were constructed (wprov_p). These weights were calculated for each sample unit by multiplying the initial weights (wstart_sp) by the $\mathrm{P} 2 / \mathrm{P} 1$ ratio, where $\mathrm{P} 2$ is the probability of having been in the previous wave while being in the current wave, and $\mathrm{P} 1$ is the probability of being in the current wave having been in the previous wave.

In order to calculate the $\mathrm{P} 1$ and $\mathrm{P} 2$ probabilities, a logistic regression was estimated choosing explanatory variables from the following list:

- Discrete variables: Region (nuts), Splitt: Household split-off, Dep_arr: household exits or entries, Incma: main source of income, Nbact: number of economically active persons in the household, Hsize: household size, Individual's sex, Tenure: housing tenure

- Continuous variables: Age and equivalent income (modified OECD scale).

Once the explanatory variables were chosen, the P1 and P2 probabilities were calculated through the SAS CATMOD procedure that models categorical data and adjusts linear models to frequency response functions. In order to avoid extreme weights, the probabilities thus obtained were trimmed at the fifth percentile.

The provisional weight for non-sample people was zero.

3.- Thirdly, the "provisional household weights" were constructed (wprov_h). This provisional weight for each household was calculated as the average of the provisional weights of the individuals making up the household.

4. The "provisional household weights" were calibrated to reflect the population distribution (through specific variables) and to obtain the "calibrated household weights" (wcal_h). The household was the unit of calibration, although individuals were also taken into account. The sample of households had to have the same structure as the population of households per region. A calibration depending on household size was also applied. The CALMAR (logit method 3) program calibrated weights for households and individuals at the same time, using a single file containing a single record per household. In the event of non-convergence, the parameters were adjusted manually.

\footnotetext{
9 “Construction of weights in the ECHP”, Eurostat DOC.PAN 165/2003-06
} 
5.- For each household, the calibrated weight wcal h was assigned to each sample person belonging to it, thereby obtaining the "base weight for sample people" (rg003). Non-sample people were assigned the value of zero. These weights were re-scaled so that the sum for all the people in the households interviewed added up to the real number of people in those households, which means that the average of these weights for sample and non-sample people was 1 . The base weight for non-sample people was zero. 
Table 1

Percentage of Individuals Remaining in the ECHP's Eight Waves (by households characteristics)

\begin{tabular}{|c|c|c|c|c|c|}
\hline Characteristics & Spain & France & UK & Germ. & Italy \\
\hline \multicolumn{6}{|l|}{ Adjusted Disposable Household Income (a). Deciles } \\
\hline Decile 1 & 43.79 & 42.35 & 56.78 & 52.47 & 52.28 \\
\hline Decile 2 & 46.34 & 46.59 & 61.03 & 56.48 & 59.03 \\
\hline Decile 3 & 46.94 & 50.00 & 64.39 & 63.74 & 56.14 \\
\hline Decile 4 & 44.52 & 51.35 & 70.72 & 61.78 & 56.15 \\
\hline Decile 5 & 43.88 & 52.26 & 71.17 & 63.72 & 57.45 \\
\hline Decile 6 & 45.53 & 56.07 & 73.65 & 67.72 & 53.32 \\
\hline Decile 7 & 48.73 & 57.21 & 72.20 & 66.38 & 52.10 \\
\hline Decile 8 & 43.79 & 56.32 & 74.44 & 65.14 & 53.76 \\
\hline Decile 9 & 42.58 & 57.51 & 71.76 & 67.08 & 52.73 \\
\hline Decile 10 & 45.46 & 54.59 & 70.11 & 69.45 & 49.21 \\
\hline Total & 45.15 & 52.42 & 68.62 & 63.39 & 54.21 \\
\hline \multicolumn{6}{|l|}{ Household head's main source of income } \\
\hline Wages and salaries & 46.02 & 55.86 & 73.03 & 65.59 & 56.21 \\
\hline Income from self-employment & 45.72 & 53.46 & 72.20 & 62.33 & 52.30 \\
\hline Pensions & 43.39 & 45.93 & 59.79 & 54.20 & 49.66 \\
\hline Unemployment/Redundancy benefits & 48.90 & 38.96 & 63.44 & 54.84 & 65.32 \\
\hline Any other social benefits or grants & 41.19 & 44.16 & 60.73 & 56.95 & 53.10 \\
\hline Private income & 34.79 & 43.32 & 48.64 & 64.08 & 44.99 \\
\hline Total & 45.15 & 52.42 & 68.62 & 63.39 & 54.21 \\
\hline \multicolumn{6}{|l|}{ Household type } \\
\hline 1-person household: aged 65 or more & 37.85 & 37.98 & 49.02 & 46.36 & 37.83 \\
\hline 1-person household: aged 30-64 & 44.08 & 50.73 & 71.22 & 64.79 & 51.02 \\
\hline 1-person household: less than 30 & 20.41 & 38.03 & 60.36 & 56.86 & 41.67 \\
\hline Single parents & 49.53 & 54.23 & 63.74 & 55.72 & 45.40 \\
\hline 2 adults without children & 44.49 & 49.41 & 69.40 & 62.06 & 48.95 \\
\hline 2 adults with one child & 48.89 & 56.36 & 76.70 & 68.46 & 53.47 \\
\hline 2 adults with two children & 47.58 & 59.73 & 76.66 & 70.82 & 61.42 \\
\hline 2 adults with three children or more & 50.77 & 59.38 & 76.53 & 65.02 & 62.60 \\
\hline $3+$ adults without children, no members aged $<25$ & 42.96 & 51.04 & 57.66 & 59.79 & 49.46 \\
\hline $3+$ adults without children, one or more $<25$ & 41.90 & 49.82 & 55.08 & 60.82 & 52.85 \\
\hline $3+$ adults with one child & 45.03 & 50.12 & 72.31 & 57.55 & 56.21 \\
\hline $3+$ adults with two children & 45.45 & 48.64 & 68.87 & 62.15 & 57.70 \\
\hline 3 +adults with three or more children & 46.34 & 42.89 & 49.68 & 63.50 & 68.89 \\
\hline Total & 45.15 & 52.42 & 68.62 & 63.39 & 54.21 \\
\hline \multicolumn{6}{|l|}{ Household head's age } \\
\hline Aged less than 30 & 46.56 & 49.39 & 60.03 & 60.12 & 50.76 \\
\hline Aged 30-64 & 45.67 & 54.80 & 73.01 & 65.92 & 56.09 \\
\hline Aged 65 or more & 41.80 & 42.52 & 57.52 & 50.03 & 45.77 \\
\hline Total & 45.15 & 52.42 & 68.62 & 63.39 & 54.21 \\
\hline \multicolumn{6}{|l|}{ Household head's sex } \\
\hline Varon & 45.93 & 53.45 & 71.66 & 65.16 & 55.30 \\
\hline Mujer & 42.18 & 49.60 & 63.64 & 58.80 & 50.46 \\
\hline Total & 45.15 & 52.42 & 68.62 & 63.39 & 54.21 \\
\hline \multicolumn{6}{|l|}{ Household head's marital status } \\
\hline Married & 46.50 & 54.45 & 74.21 & 65.37 & 55.83 \\
\hline Separated & 25.64 & 46.78 & 64.58 & 56.73 & 35.48 \\
\hline Divorced & 33.48 & 47.90 & 63.05 & 57.52 & 44.74 \\
\hline Widowed & 42.91 & 42.84 & 52.64 & 49.82 & 44.58 \\
\hline Never married & 42.49 & 49.20 & 57.38 & 61.29 & 51.16 \\
\hline Total & 45.15 & 52.42 & 68.62 & 63.45 & 54.21 \\
\hline
\end{tabular}




\begin{tabular}{|c|c|c|c|c|c|}
\hline Characteristics & Spain & France & UK & Germany & Italy \\
\hline \multicolumn{6}{|l|}{ Household head's educational attainment } \\
\hline Recognised third level & 43.95 & 58.00 & 72.27 & 68.02 & 53.59 \\
\hline Second stage of secon. & 47.08 & 54.44 & 68.43 & 65.14 & 55.65 \\
\hline Less than second stage & 45.12 & 48.43 & 67.11 & 53.89 & 53.62 \\
\hline Still at school & & 44.12 & 57.14 & 43.33 & 52.90 \\
\hline Total & 45.16 & 52.48 & 69.01 & 63.41 & 54.21 \\
\hline \multicolumn{6}{|l|}{ Tenure status } \\
\hline Owner & 45.91 & 54.67 & 73.28 & 66.61 & 55.90 \\
\hline Rent & 38.08 & 48.98 & 58.70 & 61.37 & 48.35 \\
\hline Accommodation is provided rent-free & 50.14 & 49.73 & 60.62 & 59.31 & 52.80 \\
\hline Total & 45.15 & 52.43 & 69.15 & 63.40 & 54.21 \\
\hline \multicolumn{6}{|c|}{ Number of children $(<18)$ in the household } \\
\hline 0 & 42.69 & 48.20 & 63.17 & 60.45 & 50.12 \\
\hline 1 & 46.42 & 53.61 & 74.07 & 63.74 & 54.73 \\
\hline 2 & 46.96 & 57.54 & 74.64 & 69.17 & 60.37 \\
\hline 3 & 50.00 & 60.52 & 75.18 & 63.87 & 63.02 \\
\hline 4 and more & 47.22 & 48.89 & 63.84 & 65.14 & 68.03 \\
\hline Total & 45.15 & $\mathbf{5 2 . 4 2}$ & 68.62 & 63.39 & 54.21 \\
\hline \multicolumn{6}{|c|}{ Number of full time workers in the household } \\
\hline 0 & 43.25 & 42.97 & 55.99 & 52.58 & 47.89 \\
\hline 1 & 46.27 & 52.13 & 70.83 & 63.93 & 56.08 \\
\hline 2 & 45.77 & 58.76 & 76.04 & 68.21 & 55.54 \\
\hline 3 and more & 41.32 & 52.79 & 69.10 & 61.96 & 52.28 \\
\hline Total & 45.15 & 52.42 & 68.62 & 63.39 & 54.21 \\
\hline \multicolumn{6}{|l|}{ Household size } \\
\hline 1 & 39.11 & 43.08 & 58.61 & 56.02 & 43.31 \\
\hline 2 & 44.56 & 49.52 & 69.11 & 61.59 & 48.71 \\
\hline 3 & 44.78 & 54.39 & 68.15 & 64.98 & 51.27 \\
\hline 4 & 46.80 & 57.05 & 72.25 & 67.08 & 56.26 \\
\hline 5 & 44.83 & 57.91 & 73.86 & 61.30 & 60.15 \\
\hline 6 & 44.72 & 48.90 & 67.32 & 61.90 & 55.30 \\
\hline 7 & 45.34 & 34.23 & 42.55 & 60.47 & 64.65 \\
\hline Total & 45.15 & 52.42 & 68.62 & 63.39 & 54.21 \\
\hline
\end{tabular}


Table 2

Probability of remaining in the ECHP all waves (household characteristics)

\begin{tabular}{|c|c|c|c|c|c|c|c|c|c|c|c|c|c|c|c|}
\hline & \multicolumn{3}{|c|}{ Spain } & \multicolumn{3}{|c|}{ France } & \multicolumn{3}{|c|}{ United Kingdom } & \multicolumn{3}{|c|}{ Germany } & \multicolumn{3}{|c|}{ Italy } \\
\hline & (1) & (2) & (3) & (1) & (2) & (3) & (1) & (2) & (3) & (1) & (2) & (3) & (1) & $(2)$ & (3) \\
\hline Adjusted Disposable Household Income (a) & $-1.32 \mathrm{e}-08$ & $-2.74 \mathrm{e}-08$ & $-3.47 \mathrm{e}-09$ & $6.20 \mathrm{e}-07^{*}$ & $8.76 \mathrm{e}-07 *$ & $3.23 \mathrm{e}-07$ & $1.57 \mathrm{e}-05^{*}$ & $1.69 \mathrm{e}-05^{*}$ & $6.69 \mathrm{e}-06$ & $1,15 \mathrm{e}-05^{*}$ & $1.29 \mathrm{e}-05^{*}$ & $8.87 \mathrm{e}-06^{*}$ & $-7.96 \mathrm{e}-06^{*}$ & $-8.08 \mathrm{e}-06^{*}$ & $-8.85 \mathrm{e}-06^{*}$ \\
\hline Adjusted Disposable Household Income (a) squared & $4.63 \mathrm{e}-15$ & $5.36 \mathrm{e}-15$ & $3.68 \mathrm{e}-15$ & $-4.99 \mathrm{e}-13^{*}$ & $-6.29 \mathrm{e}-13^{*}$ & $-3.38 \mathrm{e}-13^{*}$ & $-5.81 \mathrm{e}-10^{*}$ & $-5.94 \mathrm{e}-10^{*}$ & $-3.82 \mathrm{e}-10^{* *}$ & $-7.69 \mathrm{e}-11 *$ & $-8.34 \mathrm{e}-11^{*}$ & $-6.35 \mathrm{e}-11^{*}$ & $7.65 \mathrm{e}-11 *$ & $7.59 \mathrm{e}-11^{*}$ & $8.48 \mathrm{e}-11^{*}$ \\
\hline Numer of children (aged less than 18) & & & -0.02 & & & $0.29^{*}$ & & & $0.12^{*}$ & & & $0.16^{*}$ & & & $0.12 * *$ \\
\hline Household size squared & & & 0.00 & & & $-0.02^{*}$ & & & $-0.02^{*}$ & & & $-0.01 *$ & & & 0.00 \\
\hline Number of full time workers & & & -0.02 & & & $0.14^{*}$ & & & $0.16^{*}$ & & & $0.10^{*}$ & & & $0.03 * *$ \\
\hline \multicolumn{16}{|l|}{ Main source of income } \\
\hline Income from self-employment & -0.02 & -0.02 & -0.02 & $-0.10^{*}$ & $-0.10^{*}$ & $-0.10^{*}$ & -0.04 & -0.05 & -0.04 & $-0.15^{*}$ & $-0.14^{*}$ & $-0.15^{*}$ & $-0.13^{*}$ & $-0.13^{*}$ & $-0.13^{*}$ \\
\hline Pensions & 0.04 & 0.04 & 0.02 & 0.00 & -0.02 & $0.17^{*}$ & -0.06 & -0.06 & 0.08 & $0.23^{*}$ & $0.22^{*}$ & $0.32^{*}$ & 0.02 & 0.03 & 0.05 \\
\hline Unemployment/Redundancy benefits & 0.07 & 0.07 & 0.05 & $-0.32^{*}$ & $-0.34^{*}$ & $-0.19^{*}$ & -0.11 & -0.14 & 0.06 & $-0.14^{*}$ & $-0.13^{*}$ & -0.06 & $0.18^{*}$ & $0.18^{*}$ & $0.20^{*}$ \\
\hline Any other social benefits or grants & $-0.10^{*}$ & $-0.10^{*}$ & $-0.12^{*}$ & $-0.19^{*}$ & $-0.21^{*}$ & -0.07 & $-0.15^{*}$ & $-0.14^{*}$ & 0.02 & -0.02 & -0.05 & 0.06 & -0.02 & 0.00 & 0.00 \\
\hline Private income & $-0.20^{*}$ & $-0.20^{*}$ & $-0.21^{*}$ & -0.11 & $-0.13^{* *}$ & -0.03 & $-0.35^{*}$ & $-0.34^{*}$ & $-0.19^{*}$ & $0.10^{* *}$ & 0.08 & $0.17^{*}$ & $-0.24^{*}$ & $-0.24 *$ & $-0.22^{*}$ \\
\hline \multicolumn{16}{|l|}{ Household type } \\
\hline 1-person household: aged 30-64 & $0.20^{*}$ & $0.20^{*}$ & $0.20^{*}$ & 0.12 & 0.12 & $0.16^{*}$ & $0.25^{*}$ & $0.24^{*}$ & $0.31 *$ & -0.01 & 0.00 & 0.04 & $0.24^{*}$ & $0.23^{*}$ & $0.24^{*}$ \\
\hline 1-person household: less than 30 & $-0.52^{*}$ & $-0.53^{*}$ & $-0.53^{*}$ & -0.13 & -0.14 & -0.10 & 0.10 & 0.10 & 0.13 & -0.15 & -0.12 & -0.12 & 0.04 & 0.04 & 0.05 \\
\hline Single parents & $0.54^{*}$ & $0.53^{*}$ & $0.58^{*}$ & $0.28^{*}$ & $0.30 *$ & -0.03 & $0.16^{* *}$ & 0.16 & 0.17 & -0.10 & -0.05 & $-0.25^{*}$ & 0.17 & 0.17 & -0.03 \\
\hline 2 adults without children & 0.09 & 0.09 & 0.09 & 0.04 & 0.03 & 0.08 & 0.01 & 0.00 & 0.08 & -0.13 & -0.10 & -0.09 & $0.14^{*}$ & $0.14^{*}$ & $0.12^{* *}$ \\
\hline 2 adults with one child & $0.14^{*}$ & $0.14^{*}$ & $0.18^{*}$ & $0.14 * *$ & $0.15^{* *}$ & -0.02 & $0.16^{* *}$ & $0.16^{* *}$ & $0.23^{*}$ & -0.02 & 0.02 & -0.11 & $0.21^{*}$ & $0.21^{*}$ & 0.06 \\
\hline 2 adults with two children & 0.11 & 0.10 & 0.16 & $0.19^{*}$ & $0.19^{*}$ & -0.09 & 0.10 & 0.10 & $0.22 * *$ & 0.01 & 0.06 & -0.17 & $0.39 *$ & $0.39^{*}$ & 0.11 \\
\hline 2 adults with three children or more & $0.20^{*}$ & $0.19^{*}$ & $0.29 *$ & $0.23^{*}$ & $0.23^{*}$ & -0.10 & 0.15 & 0.15 & $0.43^{*}$ & -0.09 & -0.08 & $-0.32^{* *}$ & $0.40^{*}$ & $0.39^{*}$ & -0.05 \\
\hline $3+$ adults without children, no members aged less than 25 & 0.05 & 0.05 & 0.07 & 0.04 & 0.04 & $0.18^{*}$ & $-0.37^{*}$ & $-0.37 *$ & $-0.22^{* *}$ & $-0.30^{*}$ & $-0.27 *$ & $-0.23 *$ & 0.10 & 0.10 & 0.06 \\
\hline 3 +adults without children,with members aged less than 25 & -0.02 & -0.02 & 0.00 & -0.05 & -0.05 & $0.17^{*}$ & $-0.36^{*}$ & $-0.35^{*}$ & -0.15 & $-0.26 *$ & $-0.24 *$ & $-0.20^{*}$ & $0.16^{*}$ & $0.16^{*}$ & 0.11 \\
\hline $3+$ adults with one child & 0.05 & 0.05 & 0.10 & -0.05 & -0.05 & 0.03 & -0.06 & -0.06 & 0.17 & $-0.32^{*}$ & $-0.32^{*}$ & $-0.35^{*}$ & $0.24^{*}$ & $0.24^{*}$ & 0.05 \\
\hline 3 +adults with two children & 0.06 & 0.06 & 0.14 & -0.07 & -0.08 & -0.06 & -0.11 & -0.08 & $0.23 * *$ & -0.16 & $-0.17 * *$ & $-0.23 * *$ & $0.27^{*}$ & $0.27 *$ & -0.05 \\
\hline 3+adults with three or more children & 0.12 & 0.12 & $0.24 * *$ & -0.11 & -0.12 & 0.07 & $-0.56^{*}$ & $-0.56^{*}$ & 0.16 & -0.05 & -0.11 & -0.02 & $0.58^{*}$ & $0.59^{*}$ & 0.10 \\
\hline \multicolumn{16}{|l|}{ Age of household's head } \\
\hline Aged 30-64 & $-0.12^{*}$ & $-0.12^{*}$ & $-0.12^{*}$ & 0.02 & 0.02 & 0.01 & $0.08^{* *}$ & $0.07 * *$ & $0.07 * *$ & $0.09 *$ & $0.12^{*}$ & $0.08^{*}$ & $0.10^{*}$ & $0.09^{*}$ & $0.10^{*}$ \\
\hline Aged 65 or more & $-0.24 *$ & 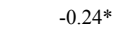 & $-0.24^{*}$ & $-0.21^{*}$ & $-0.22^{*}$ & $-0.20^{*}$ & $-0.17^{*}$ & $-0.18^{*}$ & -0.10 & $-0.47^{*}$ & $-0.44 *$ & $-0.43 *$ & -0.07 & -0.07 & -0.06 \\
\hline \multicolumn{16}{|l|}{ Sex of household's head } \\
\hline \multirow{2}{*}{\multicolumn{16}{|c|}{ Marital status of household head }} \\
\hline & & & & & & & & & & & & & & & \\
\hline Separated & $-0.60^{*}$ & $-0.59^{*}$ & $-0.60^{*}$ & -0.16 & $-0.17 * *$ & -0.15 & $-0.24 *$ & $-0.21^{*}$ & $-0.21^{*}$ & -0.13 & -0.12 & $-0.15 * *$ & $-0.41^{*}$ & $-0.41^{*}$ & $-0.40^{*}$ \\
\hline Divorced & $-0.34^{*}$ & $-0.34 *$ & $-0.35^{*}$ & $-0.16^{*}$ & $-0.16^{*}$ & $-0.16^{*}$ & $-0.30^{*}$ & $-0.29^{*}$ & $-0.31^{*}$ & $-0.15^{*}$ & $-0.15^{*}$ & $-0.15^{*}$ & $-0.17 * *$ & $-0.17^{* *}$ & -0.17 \\
\hline Widowed & -0.01 & -0.01 & -0.01 & -0.08 & $-0.09^{* *}$ & $-0.10^{* *}$ & $-0.35^{*}$ & $-0.34 *$ & $-0.36^{*}$ & $-0.17^{*}$ & $-0.20^{*}$ & $-0.17^{*}$ & $-0.12^{*}$ & $-0.11^{*}$ & $-0.13 *$ \\
\hline Never married & $-0.11^{*}$ & $-0.11^{*}$ & $-0.11^{*}$ & $-0.06 * *$ & $-0.06 * *$ & -0.05 & $-0.28^{*}$ & $-0.27 *$ & $-0.26^{*}$ & -0.01 & 0.01 & 0.00 & 0.01 & 0.01 & 0.01 \\
\hline \multicolumn{16}{|l|}{ Highest level of education completed } \\
\hline Second stage of secondary level of education & $0.08^{*}$ & & $0.08^{*}$ & $-0.07 *$ & & $-0.08^{*}$ & 0.00 & & 0.01 & -0.03 & & -0.03 & 0.05 & & 0.05 \\
\hline Less than second stage of secondary level of education & $0.05^{*}$ & & $0.05^{*}$ & $-0.11^{*}$ & & $-0.10^{*}$ & -0.02 & & -0.02 & $-0.25^{*}$ & & $-0.24^{*}$ & 0.02 & & 0.02 \\
\hline Still at school & & & & $-0.16^{*}$ & & $-0.15^{*}$ & -0.24 & & -0.32 & $-0.52^{*}$ & & $-0.54^{*}$ & $0.13^{*}$ & & $0.12^{*}$ \\
\hline \multicolumn{16}{|l|}{ Tenure status } \\
\hline Rent & $-0.20^{*}$ & $-0.20^{*}$ & $-0.20^{*}$ & $-0.11^{*}$ & $-0.11^{*}$ & $-0.10^{*}$ & $-0.23^{*}$ & $-0.24^{*}$ & $-0.20^{*}$ & $-0.09 *$ & $-0.12^{*}$ & $-0.10^{*}$ & $-0.21^{*}$ & $-0.21 *$ & $-0.21 *$ \\
\hline Accommodation is provided rent-free & $0.07 *$ & $0.08^{*}$ & $0.07 *$ & $-0.09 * *$ & $-0.08^{* *}$ & $-0.10^{*}$ & $-0.24 *$ & $-0.28^{*}$ & $-0.25^{*}$ & $-0.15^{*}$ & $-0.15^{*}$ & $-0.15^{*}$ & $-0.12^{*}$ & $-0.12^{*}$ & $-0.12 *$ \\
\hline Constant & -0.05 & 0.01 & -0.04 & 0.13 & 0.03 & 0.01 & $0.66^{*}$ & $0.65^{*}$ & $0.50^{*}$ & $0.35^{*}$ & $0.22^{*}$ & $0.30^{*}$ & -0.02 & 0.02 & -0.03 \\
\hline $\begin{array}{l}\text { Sample size } \\
\text { Sal }\end{array}$ & 22.836 & 22.837 & 22.836 & 18.134 & 18.190 & 18.134 & 12.279 & 12.440 & 12.279 & 16.027 & 16.130 & 16.027 & 21.404 & 21.424 & 21.404 \\
\hline Log likelihood & -15.561 .633 & -15565.73 & & -12.308 .747 & -12.358 .551 & -12.227 .186 & -71.810 .567 & -72.812 .006 & -71.217 .114 & -10.226 .338 & -10.335 .269 & -10.204 .355 & -14.512 .701 & -14.530 .852 & -14.505 .749 \\
\hline LR chi2 & & $(28)=312.56$ & $(33)=323.69$ & & $(28)=456.81$ & $(34)=640.00$ & & $(28)=812.87$ & $(34)=930.73$ & & 507.04 & $(34)=629.91$ & & 485.84 & $(34)=508.52$ \\
\hline Prob > chi2 & & 0.00 & 0.00 & & 0.00 & 0.00 & & 0.00 & 0.00 & & 0.00 & 0.00 & & 0.00 & 0.00 \\
\hline Pseudo R2 & 0.01 & 0.01 & 0.01 & 0.02 & 0.02 & 0.03 & 0.05 & 0.05 & 0.06 & 0.03 & 0.02 & 0.03 & 0.02 & 0.02 & 0.02 \\
\hline
\end{tabular}

Note: All children aged less than 18

(a): Modified OECD equivalent scale 
Table 3

Probability of remaining in the ECHP all waves (individual characteristics)

\begin{tabular}{|c|c|c|c|c|c|c|c|c|c|c|c|c|c|c|c|}
\hline & \multicolumn{3}{|c|}{ Spain } & \multicolumn{3}{|c|}{ France } & \multicolumn{3}{|c|}{ United Kingdom } & \multicolumn{3}{|c|}{ Germany } & \multicolumn{3}{|c|}{ Italy } \\
\hline & (1) & (2) & (3) & (1) & (2) & (3) & (1) & (2) & (3) & (1) & (2) & (3) & (1) & (2) & (3) \\
\hline Total net personal income & $2.70 \mathrm{e}-08$ & $3.75 \mathrm{e}-08 * *$ & $3.49 \mathrm{e}-08^{* *}$ & $3.86 \mathrm{e}-07 *$ & $4.59 \mathrm{e}-07 *$ & $4.27 \mathrm{e}-07^{*}$ & $2.84 \mathrm{e}-05^{*}$ & $3.02 \mathrm{e}-5^{*}$ & $3.05 \mathrm{e}-56^{*}$ & $5.24 \mathrm{e}-06^{*}$ & $5.43 \mathrm{e}-06^{*}$ & $5.32 \mathrm{e}-06^{*}$ & $-2.20 \mathrm{e}-06$ & $-1.57 \mathrm{e}-06$ & $-1.74 \mathrm{e}-06$ \\
\hline Total net personal income squared & $-6.00 \mathrm{e}-16$ & $-1.22 \mathrm{e}-15$ & $-1.13 e-15$ & $-2.05 \mathrm{e}-13^{*}$ & $-2.37 \mathrm{e}-13^{*}$ & $-2.24 \mathrm{e}-13^{*}$ & $-5.65 \mathrm{e}-10^{*}$ & $-5.86 \mathrm{e}-10^{*}$ & $-6.00 \mathrm{e}-10^{*}$ & $-2.55 \mathrm{e}-11^{*}$ & $-2.61 \mathrm{e}-11^{*}$ & $-2.61 \mathrm{e}-11^{*}$ & $8.46 \mathrm{e}-12$ & $6.26 \mathrm{e}-12$ & $6.77 \mathrm{e}-12$ \\
\hline Unemployed (aged less than 65) & -0.03 & -0.04 & -0.04 & $-0.26^{*}$ & $-0.26^{*}$ & $-0.25^{*}$ & $-0.15^{*}$ & $-0.15^{*}$ & $-0.13 * *$ & $-0.15^{*}$ & $-0.14 *$ & $-0.13^{*}$ & -0.02 & -0.03 & -0.03 \\
\hline Early retirement (aged less than 65) & $0.18^{*}$ & $0.28 *$ & $0.28 *$ & -0.04 & 0.09 & 0.09 & 0.15 & $0.28^{*}$ & $0.28^{*}$ & $0.10^{* *}$ & $0.15^{*}$ & $0.17^{*}$ & 0.04 & $0.15^{*}$ & $0.16^{*}$ \\
\hline Other economically inactive (aged less than 65) & $0.06^{*}$ & $0.08^{*}$ & $0.09 *$ & $-0.17^{*}$ & $-0.17^{*}$ & $-0.15^{*}$ & $-0.12^{*}$ & $-0.12^{*}$ & $-0.09 *$ & 0.00 & 0.00 & 0.00 & -0.01 & -0.01 & -0.01 \\
\hline Inactive (aged 65 or more) & $-0.15^{*}$ & 0.04 & 0.03 & $-0.36^{*}$ & $-0.13^{*}$ & $-0.13^{*}$ & $-0.43^{*}$ & $-0.17^{*}$ & $-0.17^{*}$ & $-0.40^{*}$ & $-0.29^{*}$ & $-0.29 *$ & $-0.29^{*}$ & -0.04 & -0.04 \\
\hline \multicolumn{16}{|l|}{ Sex of individual } \\
\hline Woman & & $0.07^{*}$ & $0.07 *$ & & $0.12^{*}$ & $0.12^{*}$ & & $0.14^{*}$ & $0.14 *$ & & $0.13^{*}$ & $0.13^{*}$ & & 0.01 & 0.01 \\
\hline Women & $0.06^{*}$ & & & $0.12^{*}$ & & & $0.15^{*}$ & & & $0.13^{*}$ & & & 0.01 & & \\
\hline \multicolumn{16}{|l|}{ Marital status of adult } \\
\hline Separated & $-0.46^{*}$ & $-0.47 *$ & $-0.46^{*}$ & $-0.27^{*}$ & $-0.27^{*}$ & $-0.26^{*}$ & $-0.42^{*}$ & $-0.44 *$ & $-0.43^{*}$ & $-0.30^{*}$ & $-0.32^{*}$ & $-0.31^{*}$ & $-0.47^{*}$ & $-0.47^{*}$ & $-0.46^{*}$ \\
\hline Divorced & $-0.39^{*}$ & $-0.40^{*}$ & $-0.39 *$ & $-0.20^{*}$ & $-0.20^{*}$ & $-0.18^{*}$ & $-0.38^{*}$ & $-0.38^{*}$ & $-0.37^{*}$ & $-0.16^{*}$ & $-0.16^{*}$ & $-0.15^{*}$ & $-0.24 * *$ & $-0.24 * *$ & $-0.24 * *$ \\
\hline Widowed & $-0.16^{*}$ & $-0.12^{*}$ & $-0.12^{*}$ & $-0.24^{*}$ & $-0.20^{*}$ & $-0.19^{*}$ & $-0.50^{*}$ & $-0.46^{*}$ & $-0.46^{*}$ & $-0.22^{*}$ & $-0.20^{*}$ & $-0.20^{*}$ & $-0.18^{*}$ & $-0.15^{*}$ & $-0.15^{*}$ \\
\hline Never married & $-0.18^{*}$ & $-0.23^{*}$ & $-0.23^{*}$ & $-0.20^{*}$ & $-0.26^{*}$ & $-0.26^{*}$ & $-0.49^{*}$ & $-0.56^{*}$ & $-0.56^{*}$ & $-0.26^{*}$ & $-0.29^{*}$ & $-0.29 *$ & $-0.16^{*}$ & $-0.24 * *$ & $-0.24 *$ \\
\hline Second stage of secondary level of education & $0.06^{* *}$ & 0.06 & 0.06 & $-0.10^{*}$ & $-0.11^{*}$ & $-0.10^{*}$ & -0.04 & -0.05 & -0.05 & $-0.06 * *$ & $-0.06^{* *}$ & $-0.06^{* *}$ & 0.00 & -0.02 & -0.01 \\
\hline Less than second stage of secondary level of education & $0.08^{*}$ & $0.11^{*}$ & $0.12^{*}$ & $-0.12^{*}$ & $-0.10^{*}$ & $-0.09 *$ & 0.01 & 0.02 & 0.03 & $-0.24^{*}$ & $-0.24 *$ & $-0.23^{*}$ & -0.04 & -0.03 & -0.02 \\
\hline Still at school & & & & $-0.21^{*}$ & $-0.25^{*}$ & $-0.26^{*}$ & -0.40 & -0.44 & -0.44 & -0.14 & -0.16 & -0.16 & 0.03 & 0.07 & $0.12^{* *}$ \\
\hline \multicolumn{16}{|l|}{ Health status of adult } \\
\hline Good & & & -0.02 & & & -0.01 & & & 0.04 & & & 0.04 & & & $-0.06^{*}$ \\
\hline Fair & & & -0.03 & & & -0.03 & & & $-0.08^{* *}$ & & & $0.08^{* *}$ & & & -0.03 \\
\hline Bad & & & $-0.10^{*}$ & & & $-0.19 *$ & & & $-0.16^{*}$ & & & -0.06 & & & $-0.15^{*}$ \\
\hline Very bad & & & $-0.42^{*}$ & & & $-0.35^{*}$ & & & $-0.57^{*}$ & & & $-0.27 *$ & & & $-0.35^{*}$ \\
\hline Constant & $-0.18^{*}$ & $-0.09 * *$ & $-0.09 * *$ & $0.25^{*}$ & $0.37 *$ & $0.37 *$ & $0.61^{*}$ & $0.74 *$ & $0.72^{*}$ & $0.43^{*}$ & $0.49 *$ & $0.45^{*}$ & $0.23^{*}$ & $0.37 * *$ & $0.40^{*}$ \\
\hline Sample size & 17.756 & 17.756 & 17.708 & 13.740 & 13.740 & 13.655 & 8.734 & 8.734 & 8.729 & 11.802 & 11.802 & 11.778 & 17.272 & 17.272 & 17.258 \\
\hline Log likelihood & -12.107 .317 & -12.093 .186 & -12.037 .561 & -93.155 .541 & -93.028 .626 & -92.249 .396 & -50.700 .169 & -50.610 .285 & -50.375 .226 & -75.239 .373 & & -74.848 .429 & -11.834 .987 & -11.815 .926 & -11.789 .277 \\
\hline LR chi2 & $(13)=195.85$ & 224.11 & $(18)=271.27$ & $(14)=408.65$ & 434.03 & $(19)=471.15$ & $(14)=573.90$ & 591.88 & $(19)=633.62$ & $(14)=402.00$ & 406.97 & $(19)=446.15$ & $(14)=204.51$ & 242.63 & $(19)=276.46$ \\
\hline Prob > chi2 & 0.00 & 0.00 & 0.00 & 0.00 & 0.00 & 0.00 & 0.00 & 0.00 & 0.00 & 0.00 & 0.00 & 0.00 & 0.00 & 0.00 & 0.00 \\
\hline Pseudo R2 & 0.01 & 0.01 & 0.01 & 0.02 & 0.02 & 0.02 & 0.05 & 0.06 & 0.06 & 0.03 & 0.03 & 0.03 & 0.01 & 0.01 & 0.01 \\
\hline
\end{tabular}

*Significant at $95 \%, * *$ Significant at $90 \%$ 
Table 4

Correlation Matrix of Longitudinal Weights

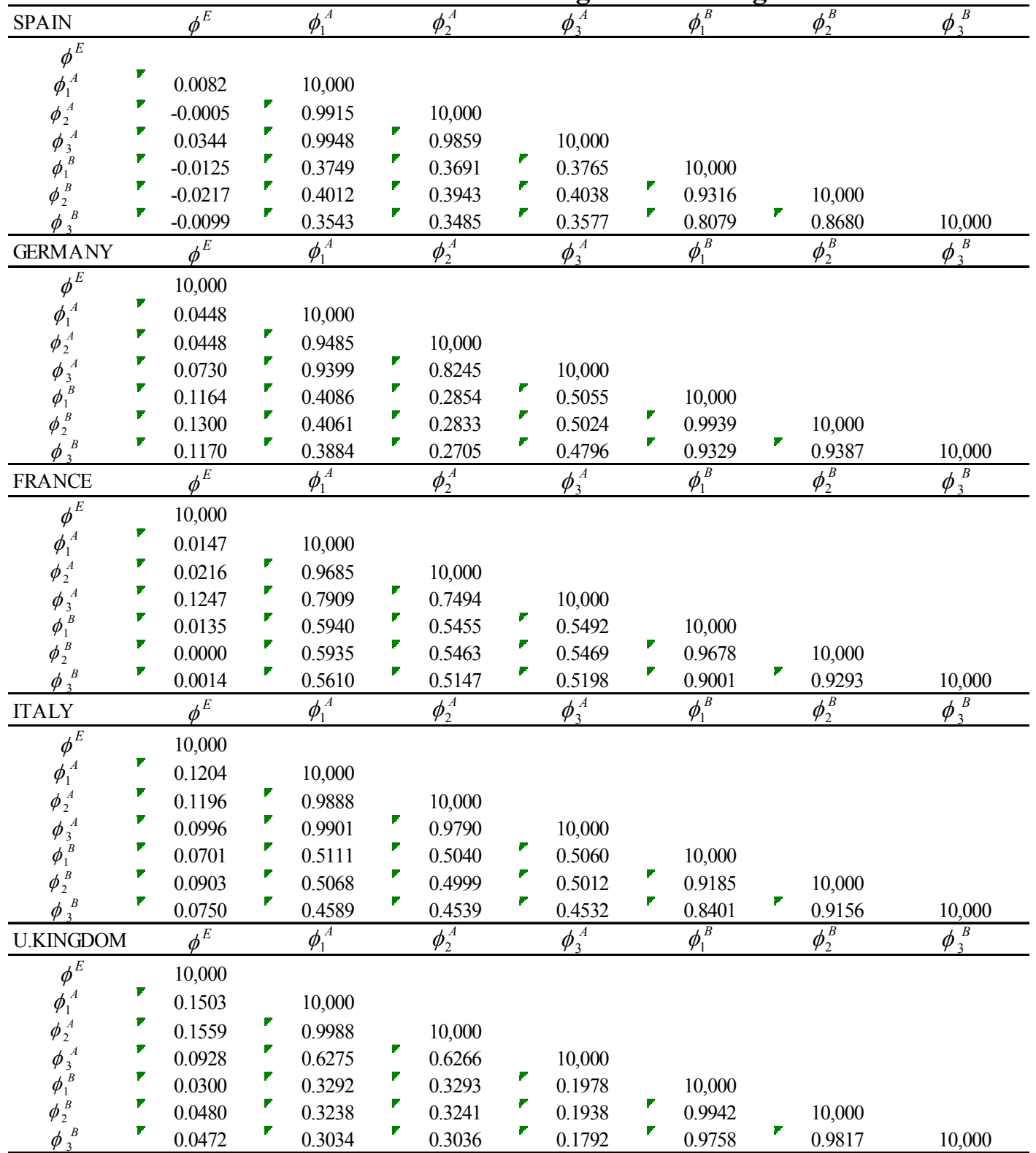

$\begin{aligned} \phi^{E} & : \text { Eurostat longitudinal weights } \\ \phi_{1}{ }^{A} \phi_{2}{ }^{A} \quad \phi_{3}^{A} & : \text { Longitudinal weights from probit models (head and hous ehold characteristics) }\end{aligned}$

$\phi_{1}^{B} \phi_{2}^{B} \phi_{3}^{B} \quad$ : Longitudinal weights from probit models (individual characteristics) 
Table 5

Frequency Distribution of the First Wave

\begin{tabular}{|c|c|c|c|c|c|c|c|c|c|c|c|c|}
\hline & \multicolumn{4}{|c|}{ Spain } & \multicolumn{4}{|c|}{ Germany } & \multicolumn{4}{|c|}{ France } \\
\hline & \multirow{2}{*}{$\begin{array}{c}f=1 \\
\begin{array}{c}\text { Wave } \\
1\end{array}\end{array}$} & \multicolumn{2}{|c|}{$f=f^{E}$} & $f=f_{2}^{A}$ & $f=1$ & & $=f^{E}$ & $f=f_{2}^{A}$ & $f=1$ & & $=f^{E}$ & $f=f_{2}^{A}$ \\
\hline & & $\begin{array}{c}\text { Wave } \\
1 \\
\end{array}$ & $\begin{array}{r}\text { Balanced } \\
\text { panel W1 }\end{array}$ & $\begin{array}{r}\text { Balanced } \\
\text { panel W1 } \\
\end{array}$ & $\begin{array}{c}\text { Wave } \\
1 \\
\end{array}$ & $\begin{array}{c}\text { Wave } \\
1 \\
\end{array}$ & $\begin{array}{r}\text { Balanced } \\
\text { panel W1 }\end{array}$ & $\begin{array}{l}\text { Balanced } \\
\text { panel W1 } \\
\end{array}$ & $\begin{array}{c}\text { Wave } \\
1 \\
\end{array}$ & $\begin{array}{c}\text { Wave } \\
1 \\
\end{array}$ & $\begin{array}{r}\text { Balanced } \\
\text { panel W1 } \\
\end{array}$ & $\begin{array}{l}\text { Balanced } \\
\text { panel W1 } \\
\end{array}$ \\
\hline Adjusted Disposable Household Income (a). Deciles & & & & & & & & & & & & \\
\hline Decile 1 & 10,01 & 9,36 & 9,29 & 9,57 & 10,00 & 11,47 & 8,22 & 9,54 & 10,02 & 9,77 & 7,57 & 9,11 \\
\hline Decile 2 & 10,00 & 9,67 & 11,20 & 10,19 & 10,01 & 8,68 & 8,17 & 9,63 & 9,99 & 9,57 & 8,87 & 9,62 \\
\hline Decile 3 & 10,00 & 9,29 & 10,11 & 10,35 & 9,99 & 9,26 & 9,76 & 10,32 & 10,01 & 9,64 & 9,36 & 9,83 \\
\hline Decile 4 & 9,99 & 9,50 & 10,12 & 9,94 & 10,02 & 8,64 & 9,07 & 9,93 & 10,00 & 9,68 & 9,64 & 9,97 \\
\hline Decile 5 & 10,01 & 10,15 & 9,31 & 9,68 & 9,98 & 9,56 & 8,82 & 9,98 & 9,99 & 10,02 & 10,48 & 10,13 \\
\hline Decile 6 & 10,00 & 10,35 & 11,38 & 10,10 & 9,99 & 9,23 & 10,10 & 10,47 & 10,00 & 9,83 & 10,04 & 10,50 \\
\hline Decile 7 & 9,99 & 9,68 & 10,73 & 10,76 & 10,00 & 9,28 & 10,68 & 10,11 & 10,02 & 10,00 & 11,07 & 10,48 \\
\hline Decile 8 & 10,01 & 10,10 & 8,45 & 9,66 & 10,00 & 10,78 & 11,22 & 9,79 & 10,00 & 10,34 & 11,30 & 10,32 \\
\hline Decile 9 & 10,00 & 10,91 & 9,21 & 9,69 & 10,01 & 10,68 & 10,60 & 9,94 & 9,98 & 10,52 & 11,27 & 10,38 \\
\hline Decile 10 & 9,99 & 10,98 & 10,19 & 10,05 & 9,99 & 12,42 & 13,36 & 10,28 & 10,00 & 10,64 & 10,40 & 9,66 \\
\hline Household head main source of income & & & & & & & & & & & & \\
\hline Wages and salaries & 57,49 & 57,70 & 61,24 & 57,40 & 72,51 & 64,21 & 69,64 & 72,45 & 62,76 & 61,94 & 68,55 & 62,81 \\
\hline Income from self-employment & 12,44 & 12,26 & 14,15 & 12,49 & 5,46 & 5,21 & 5,77 & 5,50 & 7,47 & 7,40 & 7,43 & 7,55 \\
\hline Pensions & 17,74 & 17,87 & 11,88 & 17,72 & 11,70 & 18,07 & 13,86 & 11,64 & 18,93 & 20,41 & 16,34 & 18,93 \\
\hline Unemployment/Redundancy benefits & 4,59 & 4,79 & 4,80 & 4,57 & 3,96 & 4,03 & 3,37 & 3,90 & 1,79 & 1,83 & 1,15 & 1,76 \\
\hline Any other social benefits or grants & 5,84 & 5,38 & 4,74 & 5,85 & 2,31 & 3,06 & 1,86 & 2,32 & 6,87 & 6,17 & 4,86 & 6,79 \\
\hline Private income & 1,90 & 1,99 & 3,19 & 1,97 & 4,06 & 5,42 & 5,51 & 4,18 & 2,18 & 2,25 & 1,67 & 2,16 \\
\hline Household type & & & & & & & & & & & & \\
\hline 1-person household: aged 65 or more & 2,65 & 2,43 & 1,37 & 2,65 & 3,23 & 6,37 & 4,57 & 3,25 & 4,30 & 5,10 & 2,67 & 4,31 \\
\hline 1-person household: aged 30-64 & 1,48 & 1,41 & 1,05 & 1,49 & 3,41 & 6,43 & 6,30 & 3,68 & 4,15 & 4,66 & 2,77 & 4,20 \\
\hline 1-person household: less than 30 & 0,21 & 0,20 & 0,03 & 0,20 & 1,58 & 2,43 & 2,17 & 1,57 & 1,95 & 2,19 & 1,20 & 1,95 \\
\hline Single parents & 0,93 & 0,78 & 0,46 & 0,94 & 2,54 & 2,77 & 1,03 & 2,52 & 3,45 & 3,27 & 2,25 & 3,47 \\
\hline 2 adults without children & 14,14 & 14,63 & 10,89 & 14,16 & 22,61 & 26,23 & 18,61 & 22,57 & 22,51 & 24,15 & 20,31 & 22,43 \\
\hline 2 adults with one child & 8,25 & 9,80 & 6,99 & 8,24 & 13,44 & 12,56 & 10,93 & 13,44 & 9,97 & 10,92 & 12,15 & 9,96 \\
\hline 2 adults with two children & 15,17 & 15,36 & 13,93 & 15,11 & 16,86 & 14,48 & 15,57 & 16,86 & 17,17 & 16,16 & 18,58 & 17,27 \\
\hline 2 adults with three children or more & 5,93 & 4,62 & 8,25 & 5,92 & 8,02 & 6,15 & 7,28 & 8,03 & 10,73 & 9,11 & 10,25 & 10,74 \\
\hline $3+$ adults without children,without members aged less than 25 & 10,08 & 11,60 & 8,31 & 10,16 & 5,40 & 5,64 & 7,14 & 5,29 & 3,95 & 4,30 & 5,58 & 3,99 \\
\hline $3+$ adults without children,with members aged less than 25 & 15,75 & 17,15 & 14,66 & 15,86 & 10,11 & 9,19 & 12,04 & 10,05 & 9,11 & 8,69 & 10,50 & 9,12 \\
\hline $3+$ adults with one child & 14,89 & 14,17 & 17,47 & 14,79 & 8,07 & 5,20 & 8,89 & 8,00 & 6,75 & 6,22 & 7,47 & 6,68 \\
\hline $3+$ adults with two children & 7,23 & 5,84 & 10,66 & 7,24 & 3,05 & 1,84 & 3,56 & 3,05 & 3,65 & 3,28 & 4,06 & 3,64 \\
\hline $3+$ adults with three or more children & 3,29 & 2,01 & 5,92 & 3,25 & 1,69 & 0,70 & 1,93 & 1,69 & 2,32 & 1,94 & 2,20 & 2,26 \\
\hline Household head age & & & & & & & & & & & & \\
\hline Aged less than 30 & 11,19 & 11,51 & 13,94 & 11,14 & 16,00 & 12,24 & 13,66 & 15,80 & 11,64 & 11,64 & 13,29 & 11,51 \\
\hline Aged $30-64$ & 73,00 & 72,31 & 75,60 & 72,97 & 73,92 & 70,98 & 75,09 & 74,12 & 74,15 & 72,31 & 75,22 & 74,25 \\
\hline Aged 65 or more & 15,81 & 16,19 & 10,46 & 15,89 & 10,08 & 16,77 & 11,25 & 10,09 & 14,22 & 16,05 & 11,49 & 14,24 \\
\hline Household head sex & & & & & & & & & & & & \\
\hline Male & 79,35 & 79,34 & 81,29 & 79,15 & 72,28 & 68,46 & 72,71 & 72,10 & 73,45 & 72,78 & 76,39 & 73,36 \\
\hline Female & 20,65 & 20,66 & 18,71 & 20,85 & 27,72 & 31,54 & 27,29 & 27,90 & 26,55 & 27,22 & 23,61 & 26,64 \\
\hline Household head marital status & & & & & & & & & & & & \\
\hline Married & 75,89 & 75,97 & 78,72 & 75,77 & 74,14 & 67,80 & 71,73 & 74,00 & 70,79 & 69,14 & 75,24 & 70,81 \\
\hline Separated & 1,88 & 1,66 & 0,72 & 1,92 & 1,70 & 1,86 & 1,19 & 1,71 & 0,94 & 0,96 & 0,65 & 0,93 \\
\hline Divorced & 0,99 & 1,02 & 0,73 & 0,99 & 5,35 & 6,28 & 4,36 & 5,51 & 6,79 & 7,03 & 4,98 & 6,82 \\
\hline Widowed & 7,13 & 6,89 & 5,22 & 7,21 & 5,11 & 8,40 & 5,40 & 5,19 & 6,07 & 6,74 & 4,40 & 6,01 \\
\hline Never married & 14,11 & 14,46 & 14,62 & 14,10 & 13,69 & 15,66 & 17,22 & 13,59 & 15,41 & 16,13 & 14,70 & 15,43 \\
\hline Household head highest level of education completed & & & & & & & & & & & & \\
\hline Recognised third leve & 18,49 & 19,09 & 20,83 & 17,86 & 24,90 & 26,33 & 26,24 & 25,71 & 19,83 & 20,33 & 22,34 & 20,75 \\
\hline Second stage of secon & 12,97 & 13,48 & 13,59 & 13,39 & 53,56 & 56,15 & 57,22 & 54,70 & 37,80 & 37,30 & 39,17 & 37,78 \\
\hline Less than second stag & 68,54 & 67,43 & 65,58 & 68,75 & 21,35 & 17,35 & 15,81 & 18,87 & 39,56 & 39,51 & 35,94 & 38,57 \\
\hline Still at school & & & & & 0,19 & 0,17 & 0,21 & 0,13 & 2,81 & 2,86 & 2,38 & 2,69 \\
\hline Tenure status & & & & & & & & & & & & \\
\hline Owner & 80,84 & 80,40 & 82,79 & 80,91 & 39,68 & 45,89 & 49,38 & 40,02 & 60,06 & 59,09 & 61,20 & 60,17 \\
\hline Rent & 12,98 & 13,62 & 10,70 & 12,94 & 57,79 & 50,91 & 48,13 & 57,47 & 35,79 & 36,56 & 34,57 & 35,76 \\
\hline Accommodation is provided rent-free & 6,17 & 5,98 & 6,51 & 6,15 & 2,52 & 3,21 & 2,44 & 2,52 & 4,14 & 4,35 & 4,24 & 4,07 \\
\hline Number of children $(<18)$ in the household & & & & & & & & & & & & \\
\hline 0 & 44,32 & 47,43 & 36,32 & 44,51 & 46,32 & 56,30 & 50,83 & 46,42 & 45,97 & 49,09 & 43,03 & 45,99 \\
\hline 1 & 23,49 & 24,28 & 24,69 & 23,38 & 22,84 & 19,61 & 20,45 & 22,69 & 18,28 & 18,73 & 20,63 & 18,05 \\
\hline 2 & 22,80 & 21,58 & 24,75 & 22,76 & 20,71 & 16,92 & 19,32 & 20,79 & 21,94 & 20,53 & 23,36 & 21,98 \\
\hline 3 & 6,80 & 5,36 & 9,84 & 6,89 & 7,29 & 5,44 & 7,09 & 7,20 & 9,38 & 8,17 & 9,57 & 9,96 \\
\hline 4 and more & 2,60 & 1,35 & 4,40 & 2,48 & 2,84 & 1,72 & 2,31 & 2,90 & 4,44 & 3,48 & 3,41 & 4,02 \\
\hline Number of full time workers in the household & & & & & & & & & & & & \\
\hline 0 & 23,44 & 22,94 & 17,07 & 23,27 & 17,02 & 25,69 & 18,14 & 16,44 & 23,69 & 25,10 & 17,38 & 22,77 \\
\hline 1 & 45,87 & 45,57 & 45,51 & 46,11 & 37,16 & 39,32 & 37,81 & 37,08 & 36,50 & 35,52 & 35,07 & 35,66 \\
\hline 2 & 24,94 & 25,55 & 29,46 & 25,26 & 36,80 & 28,69 & 32,18 & 37,56 & 36,84 & 36,64 & 43,91 & 38,49 \\
\hline 3 and more & 5,75 & 5,95 & 7,96 & 5,36 & 9,02 & 6,30 & 11,87 & 8,92 & 2,96 & 2,74 & 3,65 & 3,08 \\
\hline Household size & & & & & & & & & & & & \\
\hline 1 & 4,34 & 4,04 & 2,46 & 4,33 & 8,21 & 15,24 & 13,05 & 8,51 & 10,40 & 11,96 & 6,64 & 10,46 \\
\hline 2 & 14,49 & 14,93 & 11,12 & 14,51 & 23,94 & 28,09 & 19,24 & 23,83 & 24,06 & 25,74 & 21,32 & 23,84 \\
\hline 3 & 19,32 & 21,78 & 13,00 & 19,06 & 24,51 & 22,47 & 20,68 & 24,63 & 19,16 & 20,39 & 21,88 & 19,46 \\
\hline 4 & 30,63 & 31,17 & 25,68 & 31,64 & 26,92 & 22,57 & 26,87 & 27,06 & 26,11 & 24,43 & 29,22 & 26,48 \\
\hline 5 & 17,60 & 16,74 & 19,86 & 17,24 & 10,94 & 8,67 & 13,98 & 10,66 & 12,86 & 11,45 & 14,63 & 13,42 \\
\hline 6 & 7,96 & 6,93 & 12,79 & 7,80 & 3,11 & 2,00 & 2,89 & 3,08 & 4,98 & 4,18 & 4,45 & 4,62 \\
\hline 7 & 5,64 & 4,39 & 15,09 & 5,43 & 2,36 & 0,96 & 3,29 & 2,24 & 2,44 & 1,85 & 1,86 & 1,73 \\
\hline
\end{tabular}


Table 5 (Continued)

Frequency Distribution of the First Wave

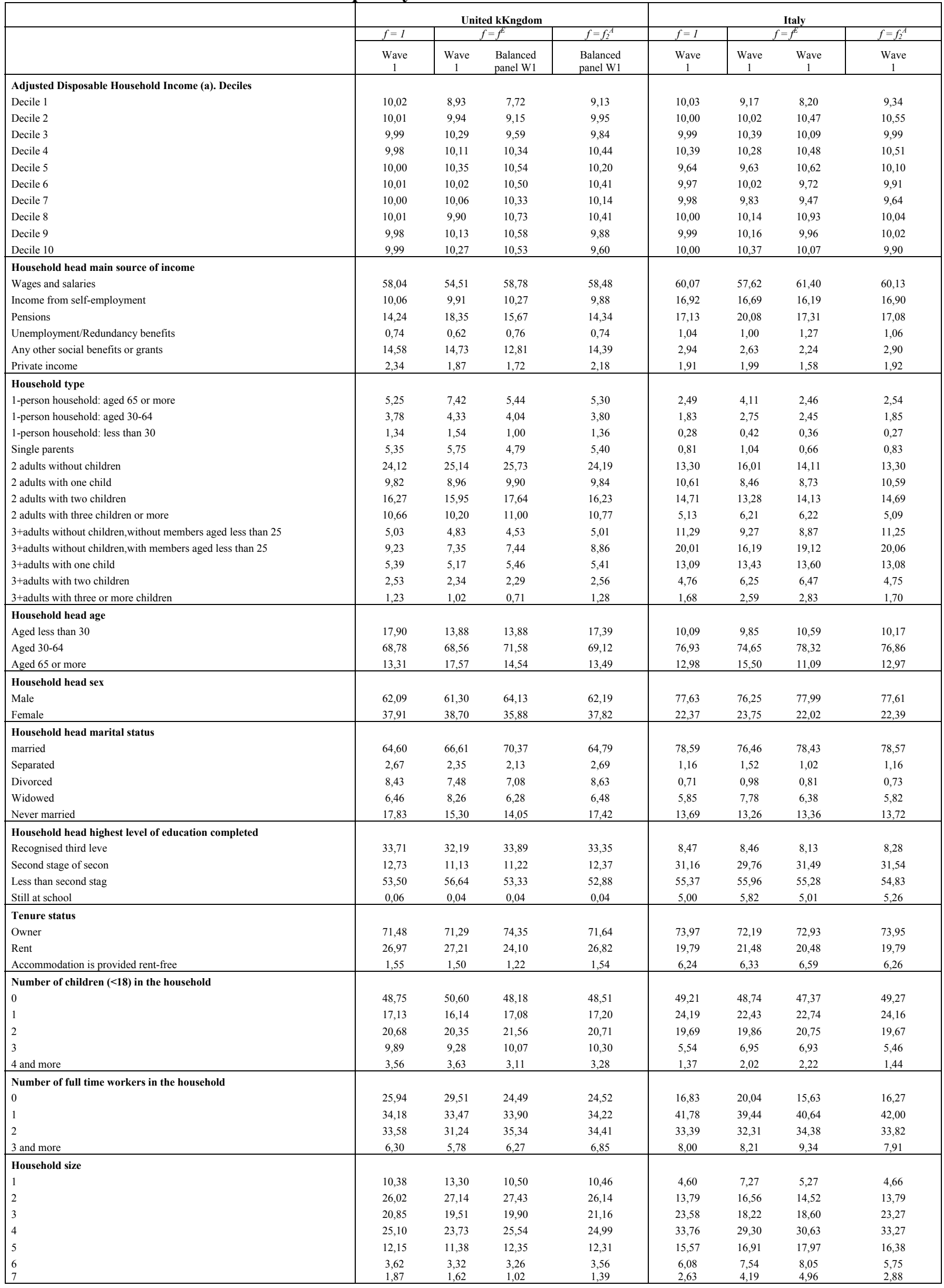


Table 6

Mobility Indicators, Waves 1-4

\begin{tabular}{|c|c|c|c|c|c|}
\hline & Spain & Germany & France & Italy & U. Kingdom \\
\hline \multicolumn{6}{|l|}{ Sub-sample $k$} \\
\hline Hart Index & 0.502 & 0.512 & 0.486 & 0.499 & 0.461 \\
\hline Shorrocks GE(0) & 0.725 & 0.732 & 0.736 & 0.674 & 0.742 \\
\hline Shorrocks GE(1) & 0.815 & 0.802 & 0.759 & 0.769 & 0.787 \\
\hline Shorrocks GE(2) & 0.785 & 0.790 & 0.602 & 0.757 & 0.678 \\
\hline Shorrocks Gini & 0.914 & 0.907 & 0.917 & 0.892 & 0.905 \\
\hline Shorrocks Atk(1) & 0.747 & 0.744 & 0.754 & 0.697 & 0.759 \\
\hline Bartholomew (Relative Matrices) & 1.571 & 1.653 & 1.387 & 1.718 & 1.676 \\
\hline Bartholomew (Absolute Matrices) & 0.957 & 0.820 & 0.784 & 1.060 & 1.077 \\
\hline Shorrocks (Relative Matrices) & 0.779 & 0.794 & 0.740 & 0.812 & 0.815 \\
\hline Shorrocks (Absolute Matrices) & 1.117 & 1.113 & 1.110 & 1.124 & 1.129 \\
\hline$\%$ Persons remaining in the same decile & 0.299 & 0.286 & 0.334 & 0.269 & 0.267 \\
\hline$\%$ Persons in the same or neighbouring decile & 0.615 & 0.608 & 0.672 & 0.580 & 0.592 \\
\hline \multicolumn{6}{|l|}{ Sub-sample $p$ (balanced panel) } \\
\hline Hart Index & 0.499 & 0.517 & 0.487 & 0.498 & 0.435 \\
\hline Shorrocks GE(0) & 0.727 & 0.730 & 0.741 & 0.676 & 0.752 \\
\hline Shorrocks GE(1) & 0.819 & 0.802 & 0.764 & 0.773 & 0.793 \\
\hline Shorrocks GE(2) & 0.799 & 0.803 & 0.619 & 0.765 & 0.684 \\
\hline Shorrocks Gini & 0.915 & 0.907 & 0.918 & 0.893 & 0.909 \\
\hline Shorrocks Atk(1) & 0.748 & 0.742 & 0.758 & 0.699 & 0.768 \\
\hline Bartholomew (Relative Matrices) & 1.572 & 1.649 & 1.388 & 1.721 & 1.634 \\
\hline Bartholomew (Absolute Matrices) & 0.957 & 0.821 & 0.781 & 1.062 & 1.058 \\
\hline Shorrocks (Relative Matrices) & 0.780 & 0.789 & 0.748 & 0.808 & 0.810 \\
\hline Shorrocks (Absolute Matrices) & 1.118 & 1.113 & 1.109 & 1.124 & 1.129 \\
\hline$\%$ Persons remaining in the same decile & 0.298 & 0.290 & 0.327 & 0.273 & 0.271 \\
\hline$\%$ Persons in the same or neighbouring decile & 0.615 & 0.611 & 0.667 & 0.583 & 0.603 \\
\hline
\end{tabular}

Sub-sample K: Individuals present in at least the ECHP's first four waves.

Sub-sample P: Balanced panel (individuals present in the ECHP's first eight waves). 
Table 7

Fields and Ok Index Decomposition, Waves 1-4

\begin{tabular}{lccc}
\hline & Mobility & $K$ & $T$ \\
\hline Sub-sample $\boldsymbol{k}$ & & & \\
Spain & 0,440 & 0,134 & 0,305 \\
Germany & 0,308 & 0,070 & 0,238 \\
France & 0,342 & 0,106 & 0,236 \\
Italy & 0,470 & 0,184 & 0,286 \\
United Kingdom & 0,424 & 0,231 & 0,193 \\
\hline Sub-sample $\boldsymbol{p}$ & & & \\
Spain & 0,436 & 0,127 & 0,310 \\
Germany & 0,302 & 0,071 & 0,231 \\
France & 0,336 & 0,114 & 0,222 \\
Italy & 0,469 & 0,191 & 0,278 \\
United Kingdom & 0,410 & 0,227 & 0,182 \\
\hline
\end{tabular}

Sub-sample K: Individuals present in at least the ECHP's first four waves.

Sub-sample P: Balanced panel (individuals present in the ECHP's first eight waves). 
Table 8

Mobility Decomposition by Population Groups, Waves 1-4

(Sub-Sample k)

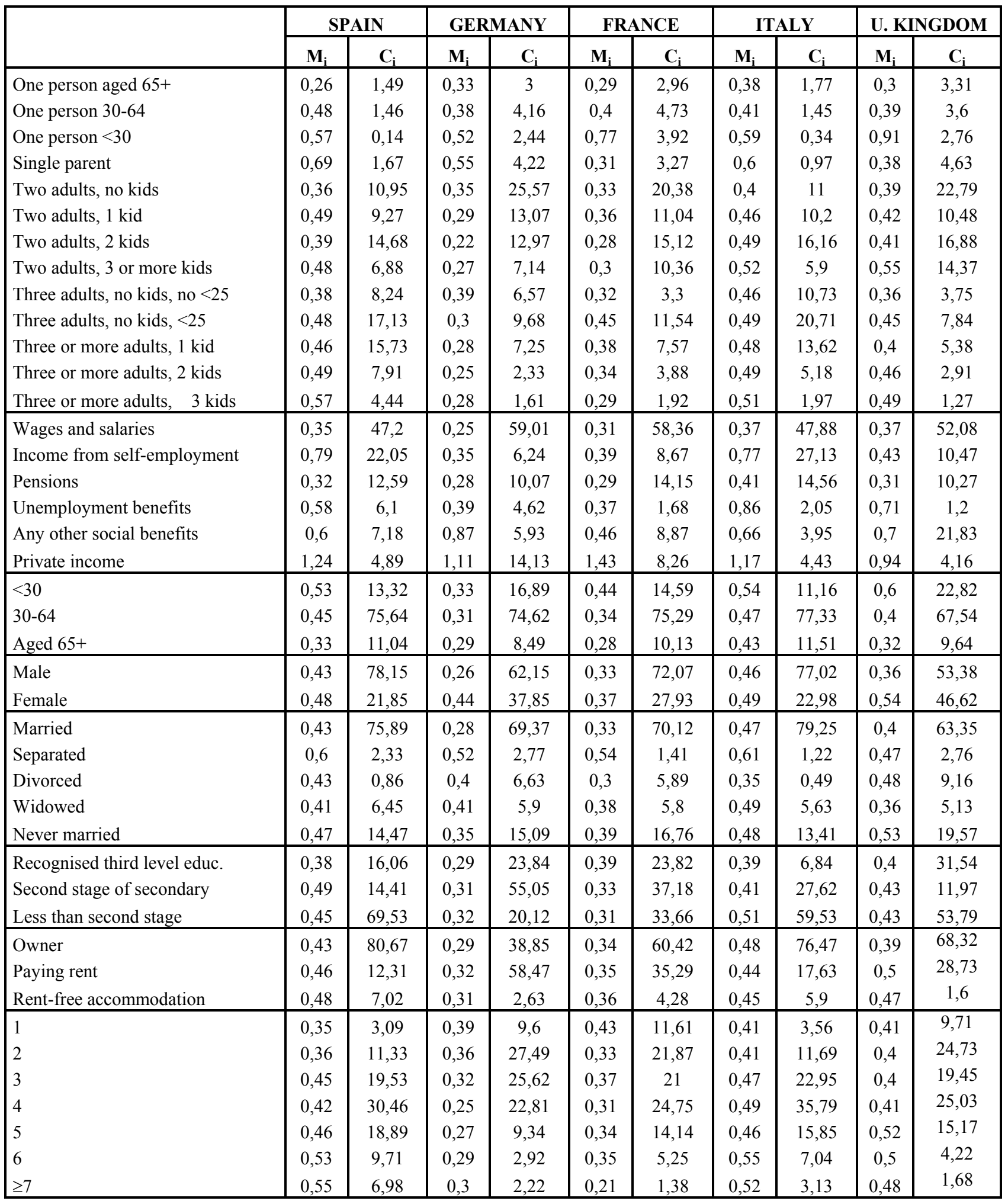

$\mathrm{M}_{\mathrm{j}}=\operatorname{group} j$ mobility, $\mathrm{C}_{\mathrm{j}}=$ group $j$ relative contribution to mobility. 
Table 9

Mobility Decomposition by Population Groups, Waves 1-4

(Sub-Sample p)

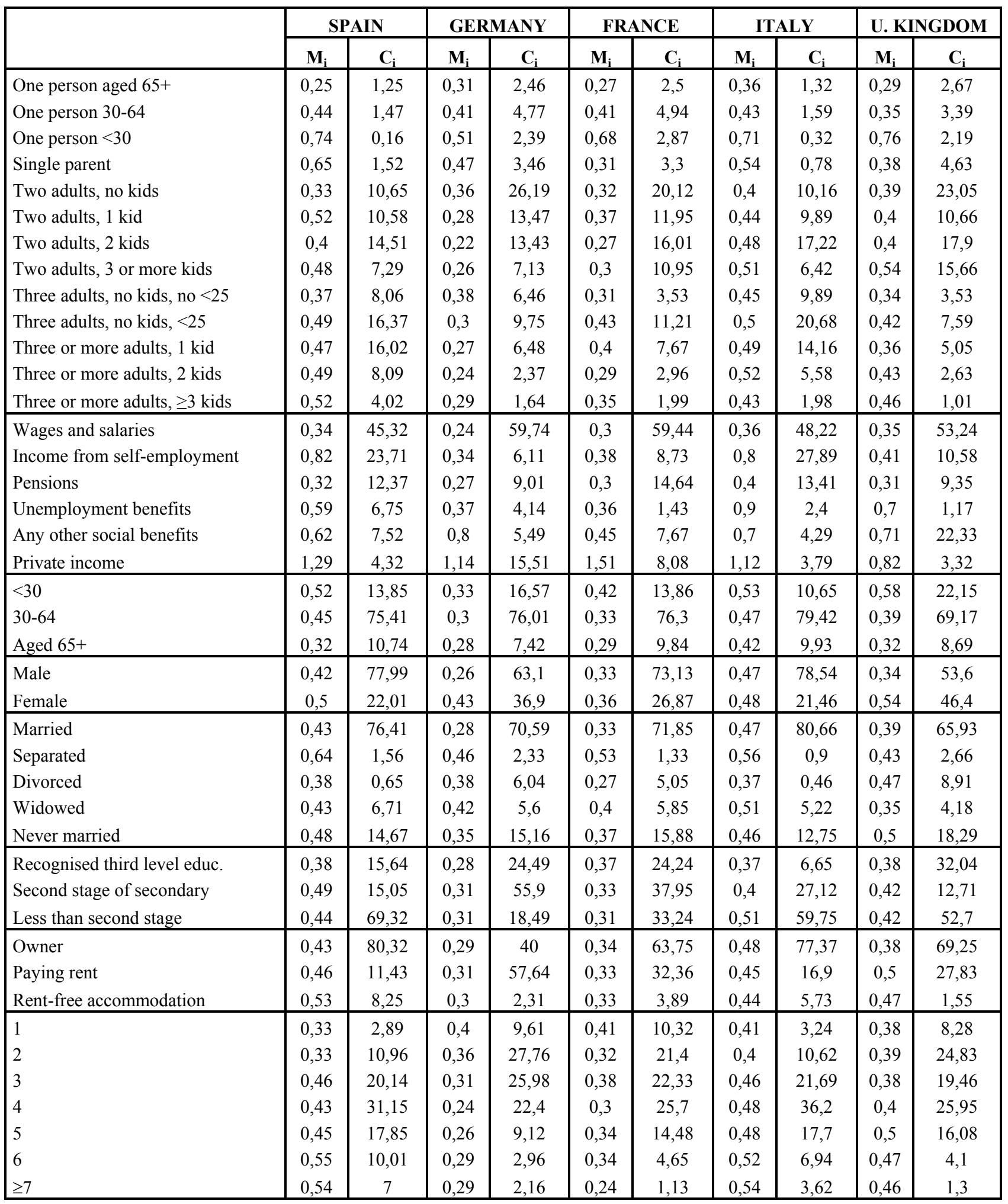

$\mathrm{M}_{\mathrm{j}}=\operatorname{group} j$ mobility, $\mathrm{C}_{\mathrm{j}}=$ group $\mathrm{j}$ relative contribution to mobility 
Table 10

Income Mobility Indicators

ECHP Waves 1-8

\begin{tabular}{|c|c|c|c|c|c|}
\hline & Spain & Germany & France & Italy & U. Kingdom \\
\hline \multicolumn{6}{|l|}{$\phi_{i}^{l}=1$} \\
\hline Hart Index & 0.593 & 0.593 & 0.588 & 0.541 & 0.589 \\
\hline Shorrocks GE(0) & 0.665 & 0.687 & 0.713 & 0.644 & 0.668 \\
\hline Shorrocks GE(1) & 0.752 & 0.751 & 0.738 & 0.729 & 0.709 \\
\hline Shorrocks GE(2) & 0.723 & 0.752 & 0.595 & 0.719 & 0.629 \\
\hline Shorrocks Gini & 0.876 & 0.875 & 0.896 & 0.867 & 0.858 \\
\hline Shorrocks Atk(1) & 0.687 & 0.699 & 0.730 & 0.666 & 0.686 \\
\hline Bartholomew (Relative Matrices) & 2.015 & 1.971 & 1.672 & 2.002 & 2.122 \\
\hline Bartholomew (Absolute Matrices) & 1.575 & 1.094 & 1.047 & 1.456 & 1.566 \\
\hline Shorrocks (Relative Matrices) & 0.867 & 0.853 & 0.820 & 0.885 & 0.893 \\
\hline Shorrocks (Absolute Matrices) & 1.148 & 1.136 & 1.132 & 1.145 & 1.151 \\
\hline$\%$ Persons remaining in the same decile & 0.220 & 0.232 & 0.262 & 0.204 & 0.197 \\
\hline$\%$ Persons in the same or neighbouring decile & 0.503 & 0.524 & 0.594 & 0.498 & 0.475 \\
\hline \multicolumn{6}{|l|}{$\phi_{i}^{l}=\phi^{E}$} \\
\hline Hart Index & 0.591 & 0.566 & 0.603 & 0.517 & 0.571 \\
\hline Shorrocks GE(0) & 0.669 & 0.689 & 0.709 & 0.652 & 0.683 \\
\hline Shorrocks GE(1) & 0.755 & 0.752 & 0.732 & 0.732 & 0.724 \\
\hline Shorrocks GE(2) & 0.728 & 0.746 & 0.593 & 0.720 & 0.646 \\
\hline Shorrocks Gini & 0.879 & 0.878 & 0.894 & 0.869 & 0.865 \\
\hline Shorrocks Atk(1) & 0.693 & 0.702 & 0.725 & 0.674 & 0.701 \\
\hline Bartholomew (Relative Matrices) & 2.087 & 1.882 & 1.738 & 1.964 & 2.070 \\
\hline Bartholomew (Absolute Matrices) & 1.709 & 1.068 & 1.078 & 1.447 & 1.500 \\
\hline Shorrocks (Relative Matrices) & 0.877 & 0.830 & 0.839 & 0.873 & 0.890 \\
\hline Shorrocks (Absolute Matrices) & 1.151 & 1.136 & 1.134 & 1.145 & 1.148 \\
\hline$\%$ Persons remaining in the same decile & 0.211 & 0.253 & 0.245 & 0.214 & 0.199 \\
\hline$\%$ Persons in the same or neighbouring decile & 0.477 & 0.546 & 0.574 & 0.503 & 0.489 \\
\hline \multicolumn{6}{|l|}{$\phi_{i}^{l}=\phi_{2}^{A}$} \\
\hline Hart Index & 0.601 & 0.582 & 0.598 & 0.543 & 0.591 \\
\hline Shorrocks GE(0) & 0.662 & 0.713 & 0.705 & 0.647 & 0.673 \\
\hline Shorrocks GE(1) & 0.748 & 0.787 & 0.724 & 0.730 & 0.716 \\
\hline Shorrocks GE(2) & 0.714 & 0.795 & 0.554 & 0.718 & 0.642 \\
\hline Shorrocks Gini & 0.875 & 0.882 & 0.894 & 0.868 & 0.860 \\
\hline Shorrocks Atk(1) & 0.684 & 0.726 & 0.722 & 0.669 & 0.692 \\
\hline Bartholomew (Relative Matrices) & 2.027 & 1.970 & 1.688 & 2.001 & 2.127 \\
\hline Bartholomew (Absolute Matrices) & 1.577 & 1.103 & 1.070 & 1.452 & 1.583 \\
\hline Shorrocks (Relative Matrices) & 0.871 & 0.856 & 0.822 & 0.885 & 0.897 \\
\hline Shorrocks (Absolute Matrices) & 1.148 & 1.137 & 1.134 & 1.145 & 1.151 \\
\hline$\%$ Persons remaining in the same decile & 0.217 & 0.230 & 0.260 & 0.204 & 0.192 \\
\hline$\%$ Persons in the same or neighbouring decile & 0.498 & 0.521 & 0.592 & 0.497 & 0.477 \\
\hline
\end{tabular}

$\phi^{E}$ Eurostat longitudinal weights (ECHP microdata files)

$\phi_{2}^{A}$ Longitudinal weights obtained from probit models (household and head characteristics) 
Table 11

Fields and Ok Mobility Index Decomposition

ECHP Waves 1-8

\begin{tabular}{lccc}
\hline & Mobility & $K$ & $T$ \\
\hline$\phi_{i}^{l=1}$ & & & \\
Spain & 0.612 & 0.456 & 0.156 \\
Germany & 0.375 & 0.170 & 0.205 \\
France & 0.415 & 0.210 & 0.205 \\
Italy & 0.582 & 0.418 & 0.164 \\
United Kingdom & 0.585 & 0.417 & 0.168 \\
\hline$\phi_{i}^{l}=\phi^{E}$ & & & \\
Spain & & & \\
Germany & 0.661 & 0.513 & 0.148 \\
France & 0.377 & 0.179 & 0.199 \\
Italy & 0.422 & 0.218 & 0.204 \\
United Kingdom & 0.555 & 0.399 & 0.156 \\
$\phi_{i}^{l}=\phi_{2}^{A}$ & 0.564 & 0.395 & 0.170 \\
Spain & & & \\
Germany & 0.614 & 0.457 & 0.156 \\
France & 0.391 & 0.189 & 0.202 \\
Italy & 0.426 & 0.222 & 0.204 \\
United Kingdom & 0.578 & 0.408 & 0.170 \\
& 0.597 & 0.433 & 0.164 \\
\hline
\end{tabular}

$\phi^{E}$ Eurostat longitudinal weights (ECHP microdata files)

$\phi_{2}^{A}$ Longitudinal weights obtained from estimating probit models (household and head characteristics) 
Table 12

Income Mobility Decomposition by Population Groups

ECHP Waves 1-8

$$
\left(\phi_{i}^{l}=1\right)
$$

\begin{tabular}{|c|c|c|c|c|c|c|c|c|c|c|}
\hline & \multicolumn{2}{|c|}{ SPAIN } & \multicolumn{2}{|c|}{ GERMANY } & \multicolumn{2}{|c|}{ FRANCE } & \multicolumn{2}{|c|}{ ITALY } & \multicolumn{2}{|c|}{ U. KINGDOM } \\
\hline & $\mathbf{M}_{\mathbf{i}}$ & $\mathbf{C}_{\mathbf{i}}$ & $\mathbf{M}_{\mathbf{i}}$ & $\mathbf{C}_{\mathrm{i}}$ & $\mathbf{M}_{\mathbf{i}}$ & $\mathbf{C}_{\mathrm{i}}$ & $\mathbf{M}_{\mathbf{i}}$ & $\mathbf{C}_{\mathrm{i}}$ & $\mathbf{M}_{\mathbf{i}}$ & $\mathbf{C}_{\mathrm{i}}$ \\
\hline One person aged $65+$ & 0.34 & 1.22 & 0.37 & 2.31 & 0.28 & 2.12 & 0.46 & 1.36 & 0.43 & 2.77 \\
\hline One person $30-64$ & 0.55 & 1.30 & 0.47 & 4.35 & 0.45 & 4.33 & 0.52 & 1.55 & 0.48 & 3.19 \\
\hline One person $<30$ & 1.23 & 0.20 & 0.63 & 2.38 & 0.92 & 3.14 & 0.67 & 0.25 & 1.26 & 2.54 \\
\hline Single parent & 0.67 & 1.12 & 0.62 & 3.70 & 0.41 & 3.48 & 0.58 & 0.68 & 0.71 & 5.99 \\
\hline Two adults, no kids & 0.45 & 10.17 & 0.43 & 25.24 & 0.36 & 18.23 & 0.47 & 9.71 & 0.48 & 20.05 \\
\hline Two adults, 1 kid & 0.54 & 7.86 & 0.35 & 13.52 & 0.46 & 11.93 & 0.53 & 9.45 & 0.55 & 10.41 \\
\hline Two adults, 2 kids & 0.57 & 14.75 & 0.32 & 15.98 & 0.35 & 16.48 & 0.53 & 15.04 & 0.61 & 18.87 \\
\hline Two adults, 3 or more kids & 0.61 & 6.70 & 0.29 & 6.32 & 0.41 & 12.12 & 0.61 & 6.19 & 0.79 & 16.16 \\
\hline Three adults, no kids, no $<25$ & 0.49 & 7.73 & 0.40 & 5.49 & 0.36 & 3.36 & 0.57 & 10.05 & 0.39 & 2.83 \\
\hline Three adults, no kids, $<25$ & 0.72 & 17.26 & 0.37 & 9.64 & 0.53 & 11.13 & 0.68 & 22.96 & 0.60 & 7.54 \\
\hline Three or more adults, 1 kid & 0.73 & 17.59 & 0.38 & 7.52 & 0.52 & 8.14 & 0.68 & 15.78 & 0.57 & 5.53 \\
\hline Three or more adults, 2 kids & 0.83 & 9.81 & 0.28 & 2.22 & 0.48 & 3.91 & 0.57 & 4.93 & 0.69 & 3.00 \\
\hline Three or more adults, $\geq 3$ kids & 0.78 & 4.28 & 0.29 & 1.33 & 0.36 & 1.64 & 0.56 & 2.05 & 0.73 & 1.11 \\
\hline Wages and salaries & 0.52 & 50.16 & 0.32 & 63.70 & 0.39 & 62.19 & 0.48 & 51.55 & 0.52 & 55.05 \\
\hline Income from self-employment & 0.90 & 18.49 & 0.40 & 5.73 & 0.50 & 9.13 & 0.84 & 23.65 & 0.60 & 10.91 \\
\hline Pensions & 0.50 & 13.92 & 0.34 & 9.01 & 0.30 & 12.00 & 0.56 & 15.12 & 0.42 & 8.88 \\
\hline Unemployment benefits & 0.79 & 6.40 & 0.45 & 4.09 & 0.42 & 1.36 & 0.88 & 1.90 & 0.97 & 1.13 \\
\hline Any other social benefits & 0.85 & 7.43 & 0.91 & 5.04 & 0.58 & 8.06 & 0.86 & 4.27 & 0.94 & 20.83 \\
\hline Private income & 1.50 & 3.60 & 1.14 & 12.43 & 1.67 & 7.26 & 1.29 & 3.51 & 1.13 & 3.20 \\
\hline$<30$ & 0.70 & 13.20 & 0.40 & 16.29 & 0.51 & 13.50 & 0.65 & 10.57 & 0.77 & 20.62 \\
\hline $30-64$ & 0.63 & 75.67 & 0.37 & 76.29 & 0.42 & 78.14 & 0.58 & 78.65 & 0.57 & 71.26 \\
\hline Aged 65+ & 0.47 & 11.13 & 0.35 & 7.42 & 0.30 & 8.36 & 0.57 & 10.78 & 0.43 & 8.12 \\
\hline Male & 0.60 & 79.54 & 0.33 & 64.55 & 0.41 & 74.17 & 0.58 & 78.72 & 0.52 & 57.28 \\
\hline Female & 0.65 & 20.46 & 0.52 & 35.45 & 0.43 & 25.83 & 0.59 & 21.28 & 0.71 & 42.72 \\
\hline Married & 0.61 & 77.88 & 0.35 & 71.72 & 0.41 & 72.13 & 0.57 & 79.88 & 0.55 & 66.17 \\
\hline Separated & 0.73 & 1.27 & 0.65 & 2.65 & 0.60 & 1.22 & 0.61 & 0.80 & 0.63 & 2.73 \\
\hline Divorced & 0.55 & 0.66 & 0.44 & 5.74 & 0.38 & 5.74 & 0.46 & 0.46 & 0.71 & 9.35 \\
\hline Widowed & 0.56 & 6.24 & 0.45 & 4.79 & 0.42 & 4.96 & 0.63 & 5.20 & 0.46 & 3.93 \\
\hline Never married & 0.64 & 13.95 & 0.42 & 14.88 & 0.46 & 15.90 & 0.62 & 13.66 & 0.70 & 17.78 \\
\hline Recognised third level educ. & 0.49 & 14.30 & 0.36 & 25.67 & 0.47 & 24.63 & 0.44 & 6.29 & 0.54 & 32.16 \\
\hline Second stage of secondary & 0.61 & 13.39 & 0.38 & 55.98 & 0.40 & 37.67 & 0.51 & 27.88 & 0.63 & 13.38 \\
\hline Less than second stage & 0.65 & 72.31 & 0.36 & 17.56 & 0.37 & 32.71 & 0.64 & 59.79 & 0.60 & 52.51 \\
\hline Owner & 0.60 & 80.93 & 0.36 & 40.35 & 0.41 & 62.18 & 0.58 & 76.40 & 0.54 & 69.54 \\
\hline Paying rent & 0.61 & 10.85 & 0.38 & 57.23 & 0.42 & 33.49 & 0.60 & 18.06 & 0.71 & 27.69 \\
\hline Rent-free accommodation & 0.73 & 8.21 & 0.38 & 2.41 & 0.46 & 4.33 & 0.53 & 5.54 & 0.77 & 1.79 \\
\hline 1 & 0.44 & 2.72 & 0.47 & 9.03 & 0.47 & 9.59 & 0.50 & 3.16 & 0.56 & 8.53 \\
\hline 2 & 0.45 & 10.49 & 0.44 & 27.11 & 0.36 & 19.43 & 0.48 & 10.16 & 0.49 & 22.00 \\
\hline 3 & 0.55 & 17.36 & 0.38 & 25.14 & 0.45 & 21.70 & 0.56 & 21.46 & 0.54 & 19.06 \\
\hline 4 & 0.62 & 32.32 & 0.34 & 25.76 & 0.40 & 27.59 & 0.60 & 36.37 & 0.61 & 27.60 \\
\hline 5 & 0.67 & 19.22 & 0.31 & 8.81 & 0.44 & 15.12 & 0.63 & 18.70 & 0.76 & 17.06 \\
\hline 6 & 0.79 & 10.16 & 0.31 & 2.54 & 0.51 & 5.73 & 0.64 & 6.83 & 0.72 & 4.37 \\
\hline$\geq 7$ & 0.84 & 7.73 & 0.27 & 1.60 & 0.22 & 0.83 & 0.62 & 3.32 & 0.70 & 1.39 \\
\hline
\end{tabular}

$\mathrm{M}_{\mathrm{j}}=$ group $\mathrm{j}$ mobility, $\mathrm{C}_{\mathrm{j}}=$ group $j$ relative contribution to mobility. 
Table 13

Income Mobility Decomposition by Population Groups, Waves 1-8

ECHP Waves 1-8

$\left(\phi_{i}^{l}=\phi^{E}\right)$ Eurostat longitudinal weights

\begin{tabular}{|c|c|c|c|c|c|c|c|c|c|c|}
\hline & \multicolumn{2}{|c|}{ SPAIN } & \multicolumn{2}{|c|}{ GERMANY } & \multicolumn{2}{|c|}{ FRANCE } & \multicolumn{2}{|c|}{ ITALY } & \multicolumn{2}{|c|}{ U. KINGDOM } \\
\hline & $\mathbf{M}_{\mathrm{i}}$ & $\mathbf{C}_{\mathrm{i}}$ & $\mathbf{M}_{\mathbf{i}}$ & $\mathbf{C}_{\mathrm{i}}$ & $\mathbf{M}_{\mathbf{i}}$ & $\mathbf{C}_{\mathrm{i}}$ & $\mathbf{M}_{\mathbf{i}}$ & $\mathbf{C}_{\mathrm{i}}$ & $\mathbf{M}_{\mathbf{i}}$ & $\mathbf{C}_{\mathrm{i}}$ \\
\hline One person aged $65+$ & 0.32 & 0.67 & 0.42 & 5.14 & 0.28 & 1.80 & 0.48 & 2.13 & 0.43 & 4.16 \\
\hline One person $30-64$ & 0.50 & 0.80 & 0.44 & 7.38 & 0.44 & 2.89 & 0.52 & 2.30 & 0.47 & 3.39 \\
\hline One person $<30$ & 1.62 & 0.08 & 0.55 & 3.14 & 0.87 & 2.49 & 0.59 & 0.38 & 1.18 & 2.09 \\
\hline Single parent & 0.66 & 0.46 & 0.63 & 1.71 & 0.40 & 2.12 & 0.56 & 0.67 & 0.66 & 5.65 \\
\hline Two adults, no kids & 0.45 & 7.38 & 0.43 & 21.00 & 0.36 & 17.17 & 0.44 & 11.19 & 0.45 & 20.63 \\
\hline Two adults, 1 kid & 0.50 & 5.34 & 0.38 & 11.06 & 0.46 & 13.35 & 0.52 & 8.20 & 0.52 & 9.18 \\
\hline Two adults, 2 kids & 0.56 & 11.84 & 0.34 & 14.09 & 0.35 & 15.56 & 0.50 & 12.75 & 0.62 & 19.28 \\
\hline Two adults, 3 or more kids & 0.63 & 7.83 & 0.29 & 5.67 & 0.40 & 9.82 & 0.59 & 6.57 & 0.80 & 15.59 \\
\hline Three adults, no kids, no $<25$ & 0.52 & 6.50 & 0.40 & 7.50 & 0.43 & 5.64 & 0.55 & 8.72 & 0.39 & 3.17 \\
\hline Three adults, no kids, $<25$ & 0.80 & 17.82 & 0.35 & 11.16 & 0.54 & 13.36 & 0.64 & 21.97 & 0.57 & 7.54 \\
\hline Three or more adults, $1 \mathrm{kid}$ & 0.78 & 20.49 & 0.38 & 9.06 & 0.53 & 9.46 & 0.64 & 15.62 & 0.58 & 5.58 \\
\hline Three or more adults, 2 kids & 0.85 & 13.77 & 0.20 & 1.91 & 0.48 & 4.58 & 0.55 & 6.38 & 0.68 & 2.75 \\
\hline Three or more adults, $\geq 3$ kids & 0.78 & 7.01 & 0.23 & 1.19 & 0.34 & 1.77 & 0.61 & 3.13 & 0.75 & 0.95 \\
\hline Wages and salaries & 0.57 & 52.77 & 0.32 & 59.73 & 0.40 & 64.27 & 0.48 & 52.69 & 0.51 & 52.61 \\
\hline Income from self-employment & 0.92 & 19.75 & 0.41 & 6.28 & 0.49 & 8.66 & 0.77 & 22.55 & 0.61 & 11.02 \\
\hline Pensions & 0.51 & 9.15 & 0.33 & 11.96 & 0.33 & 12.89 & 0.53 & 16.54 & 0.41 & 11.32 \\
\hline Unemployment benefits & 0.75 & 5.43 & 0.45 & 4.04 & 0.40 & 1.10 & 0.82 & 1.89 & 0.96 & 1.29 \\
\hline Any other social benefits & 0.84 & 6.03 & 0.91 & 4.49 & 0.54 & 6.22 & 0.78 & 3.15 & 0.91 & 20.63 \\
\hline Private income & 1.42 & 6.85 & 0.92 & 13.50 & 1.73 & 6.86 & 1.11 & 3.18 & 1.03 & 3.13 \\
\hline$<30$ & 0.74 & 15.59 & 0.42 & 15.09 & 0.49 & 15.54 & 0.60 & 11.46 & 0.73 & 17.90 \\
\hline $30-64$ & 0.67 & 76.74 & 0.37 & 73.89 & 0.43 & 76.02 & 0.55 & 77.77 & 0.56 & 71.23 \\
\hline Aged 65+ & 0.48 & 7.67 & 0.37 & 11.02 & 0.31 & 8.44 & 0.54 & 10.77 & 0.42 & 10.87 \\
\hline Male & 0.65 & 79.66 & 0.33 & 63.30 & 0.42 & 75.15 & 0.55 & 77.07 & 0.50 & 57.14 \\
\hline Female & 0.72 & 20.34 & 0.51 & 36.70 & 0.44 & 24.85 & 0.58 & 22.93 & 0.67 & 42.86 \\
\hline Married & 0.66 & 78.53 & 0.36 & 68.51 & 0.42 & 74.99 & 0.54 & 76.81 & 0.55 & 68.41 \\
\hline Separated & 0.73 & 0.79 & 0.57 & 1.78 & 0.57 & 0.88 & 0.50 & 0.91 & 0.58 & 2.17 \\
\hline Divorced & 0.47 & 0.52 & 0.41 & 4.77 & 0.38 & 4.47 & 0.42 & 0.62 & 0.68 & 8.53 \\
\hline Widowed & 0.57 & 4.52 & 0.49 & 6.96 & 0.42 & 4.37 & 0.62 & 7.17 & 0.44 & 4.92 \\
\hline Never married & 0.71 & 15.64 & 0.39 & 17.82 & 0.44 & 15.25 & 0.60 & 14.49 & 0.64 & 15.93 \\
\hline Recognised third level educ. & 0.61 & 19.23 & 0.38 & 26.58 & 0.47 & 24.88 & 0.46 & 6.72 & 0.52 & 31.28 \\
\hline Second stage of secondary & 0.61 & 12.46 & 0.38 & 58.01 & 0.41 & 37.88 & 0.49 & 27.90 & 0.62 & 12.25 \\
\hline Less than second stage & 0.69 & 68.31 & 0.35 & 14.56 & 0.38 & 32.11 & 0.60 & 59.67 & 0.58 & 54.84 \\
\hline Owner & 0.66 & 82.61 & 0.36 & 47.44 & 0.42 & 61.38 & 0.55 & 72.93 & 0.52 & 69.11 \\
\hline Paying rent & 0.64 & 10.32 & 0.39 & 50.01 & 0.42 & 34.10 & 0.57 & 20.89 & 0.67 & 28.41 \\
\hline Rent-free accommodation & 0.72 & 7.06 & 0.39 & 2.51 & 0.45 & 4.52 & 0.52 & 6.18 & 0.76 & 1.65 \\
\hline 1 & 0.42 & 1.55 & 0.45 & 15.66 & 0.46 & 7.18 & 0.51 & 4.82 & 0.52 & 9.69 \\
\hline 2 & 0.45 & 7.55 & 0.43 & 22.14 & 0.36 & 17.94 & 0.44 & 11.63 & 0.46 & 22.41 \\
\hline 3 & 0.54 & 10.64 & 0.40 & 22.05 & 0.45 & 23.52 & 0.54 & 18.04 & 0.51 & 18.14 \\
\hline 4 & 0.62 & 24.06 & 0.36 & 25.62 & 0.41 & 28.64 & 0.57 & 31.75 & 0.61 & 27.63 \\
\hline 5 & 0.66 & 19.94 & 0.28 & 10.43 & 0.47 & 16.40 & 0.61 & 19.64 & 0.77 & 16.80 \\
\hline 6 & 0.78 & 15.14 & 0.33 & 2.50 & 0.49 & 5.14 & 0.61 & 8.83 & 0.70 & 4.05 \\
\hline$\geq 7$ & 0.92 & 21.11 & 0.18 & 1.60 & 0.26 & 1.17 & 0.59 & 5.28 & 0.71 & 1.28 \\
\hline
\end{tabular}

$\mathrm{M}_{\mathrm{j}}=\operatorname{group} j$ mobility, $\mathrm{C}_{\mathrm{j}}=$ group $j$ relative contribution to mobility. 
Table 14

Income Mobility Decomposition by Population Groups, Waves 1-8

ECHP Waves 1-8

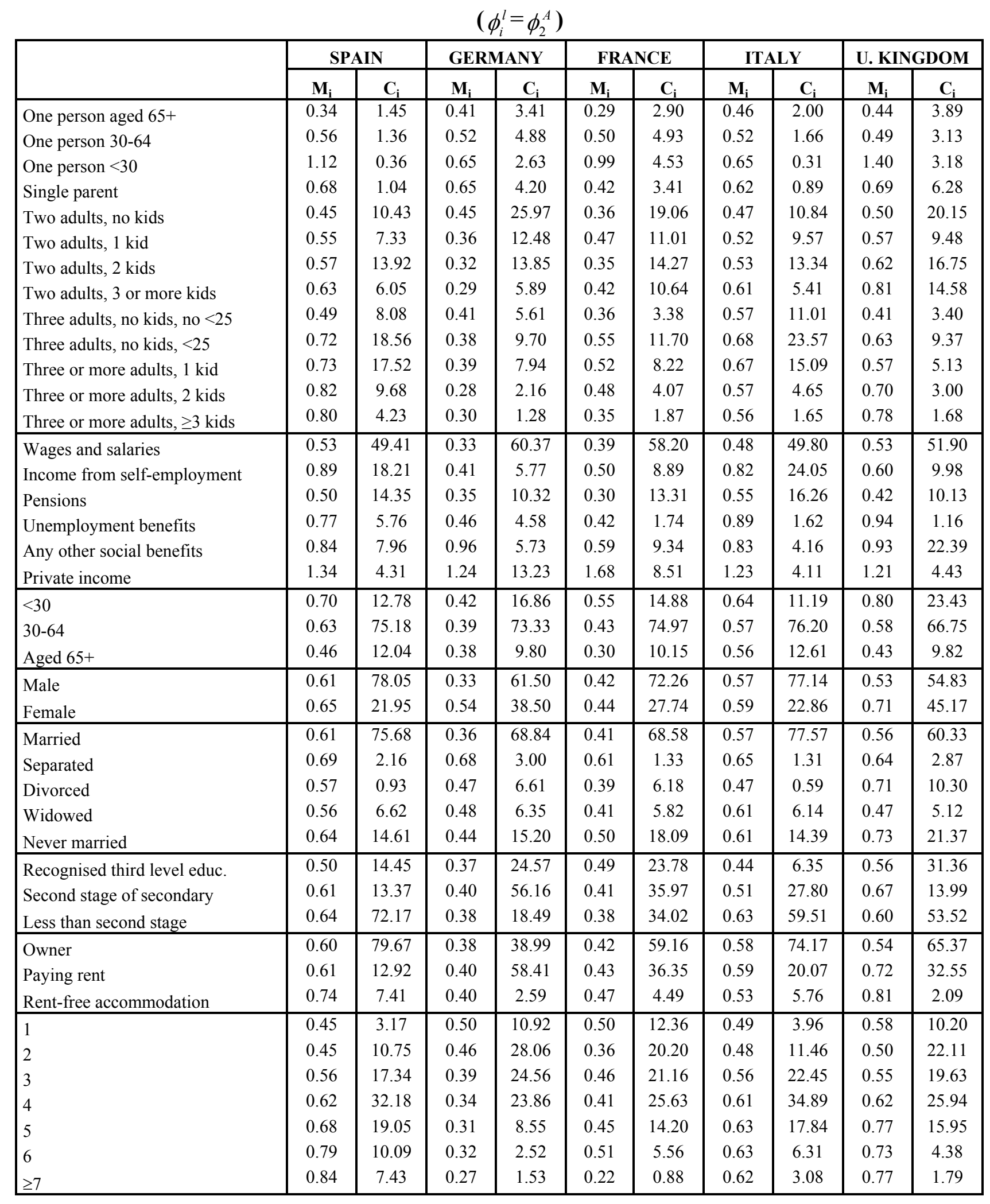

$\mathrm{M}_{\mathrm{j}}=\operatorname{group} j$ mobility, $\mathrm{C}_{\mathrm{j}}=$ group $j$ relative contribution to mobility.

$\phi_{2}^{A}$ Longitudinal weights obtained from probit models (household and head characteristics) 
Figure 1

Attrition in the ECHP, 1994-2001

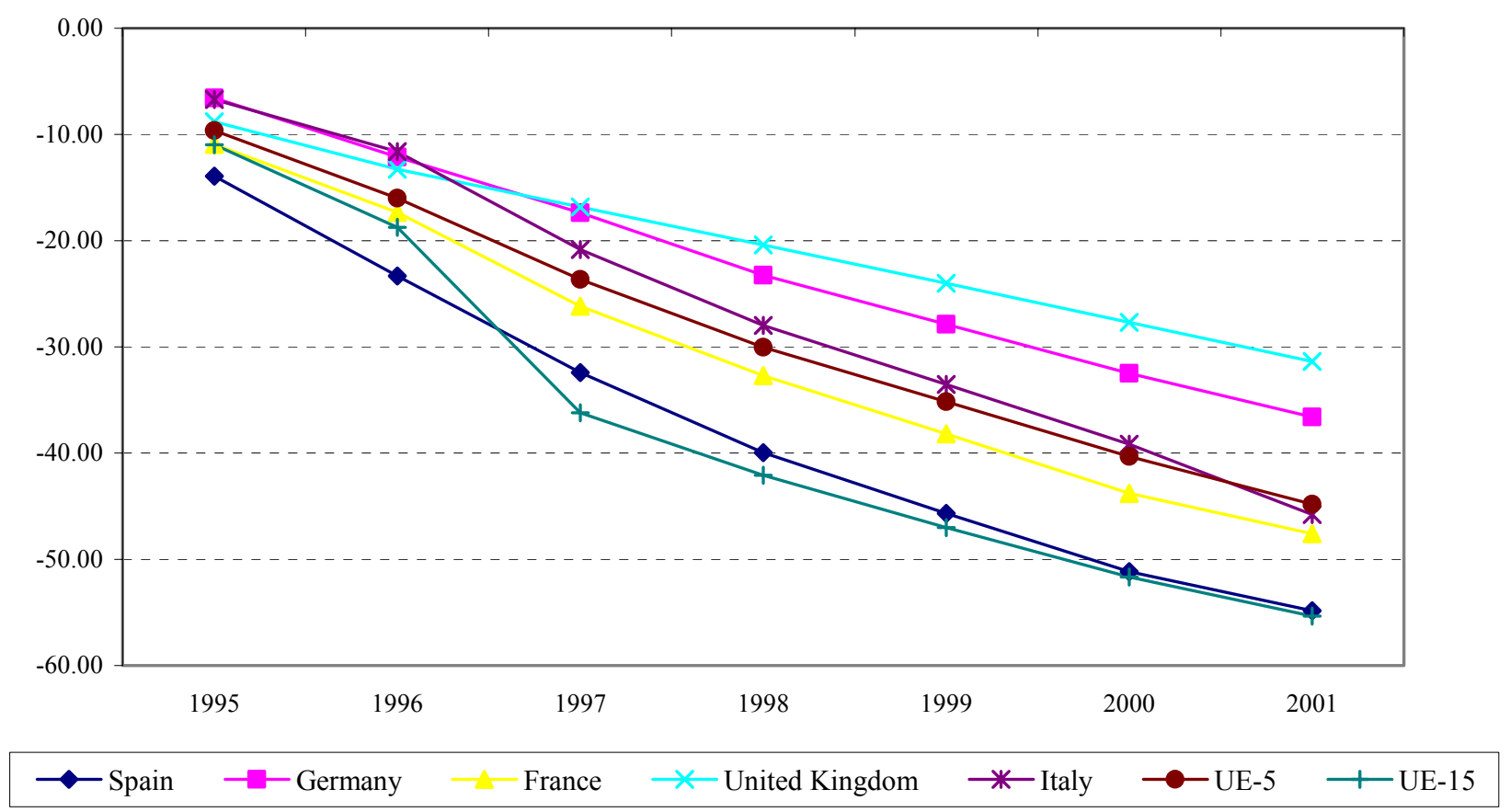

